\title{
Sorbent Materials Characterization Based on Mechanical or Thermal Pretreated Montmorillonite Modified by Surfactant Loading for Improved Chromium Retention
}

\author{
César Fernández Morantes • Florencia Yarza • \\ María L. Montes • Roberto C. Mercader • \\ Gustavo Curutchet • Rosa M. Torres Sánchez
}

Received: 8 October 2019 / Accepted: 6 January 2020

(C) Springer Nature Switzerland AG 2020

\begin{abstract}
To improve hexavalent chromium ( $\mathrm{Cr}(\mathrm{VI}))$ retention of montmorillonite $(\mathrm{Mt})$ at $\mathrm{pH} 3, \mathrm{Mt}$ sample was subjected to different treatments: thermal ones at $600{ }^{\circ} \mathrm{C}$ or $950^{\circ} \mathrm{C}, 2 \mathrm{~h}$, or mechanical grinding for $300 \mathrm{~s}$. Then, the obtained products were loaded with different octadecyl trimethyl ammonium loading and 50\% and $100 \%$ of Mt cation exchange capacity (CEC). The samples were characterized by several techniques at each stage. Differential thermogravimetric analysis (DTGA) performed on the products allowed determining the actual surfactant amount related to the internal or external surface by cation exchange and Van der Waals (VdW) mechanisms, respectively, taking into account the CEC of the thermal or mechanical pretreated Mt base sample used. X-ray diffraction (XRD) analyses
\end{abstract}

Electronic supplementary material The online version of this article (https://doi.org/10.1007/s11270-020-4403-7) contains supplementary material, which is available to authorized users.

C. F. Morantes · F. Yarza · R. M. Torres Sánchez $(\bowtie)$

CETMIC-CCT-La Plata - CIC, Camino Centenario y 506, (1897)

M. B. Gonnet, La Plata, Argentina

e-mail: rosats@ cetmic.unlp.edu.ar

e-mail: rosa.torres@gmail.com

C. F. Morantes · G. Curutchet

Lab. 3iA, Universidad Nacional de San Martín, Av. 25 de Mayo y

Francia (1650),, San Martín, Buenos Aires, Argentina

M. L. Montes · R. C. Mercader

Departamento de Física, Facultad de Ciencias Exactas, IFLP, Instituto de Física La Plata - CONICET CCT-La Plata, UNLP, La Plata, Argentina revealed that the surfactant loading allowed the reversal of the collapsed interlayer after both treatments. The samples subjected to the thermal treatment at $600{ }^{\circ} \mathrm{C}$ and the raw Mt samples exhibit higher positive zeta potential values than the mechanical pretreated Mt ones with $100 \%$ of the CEC surfactant loaded at $\mathrm{pH} 3$. This was directly related to the external surface covered by the surfactant. The agreement between the results of the surfactant coverage on the external surface and $\mathrm{Cr}(\mathrm{VI})$ removal at $\mathrm{pH} 3$ indicates that the electrostatic mechanism is the main driving force for the sorption of $\mathrm{Cr}(\mathrm{VI})$. These synthesized sorbents achieve similar Cr(VI) retention using less than half the surfactant amount of already published studies.

Keywords Montmorillonite - Thermal and mechanical treatments $\cdot$ Structure modification $\cdot$ Chromium retention

\section{Introduction}

In recent years, the structures of clay minerals have been modified for technological, environmental, and industrial processes. For example, surfactant loading, which turns clays into the so-called organo-clays, changes their character from hydrophilic to hydrophobic thus modifying the system coagulation state and aggregation of particles (Yamagata et al. 2012; Huang et al. 2017) and generating the reversal of the external surface electric charge (Bianchi et al. 2013). In addition, the alterations brought about in the interlayer thickness protect the 
mineral structure from acid degradation (Madejová et al. 2012).

Organo-clays have extended the technological applications of clays from barriers to biomedical uses, catalytic reactions, reinforcement of polymers, adsorption of anions, or nonpolar organic contaminants for wastewater treatment (Patel et al. 2006; de Paiva et al. 2008; Qurie et al. 2013; Savas and Hancer 2015; Zhao et al. 2017; Jayrajsinh et al. 2017).

Thermal and mechanical treatments have been applied to modify the structure of montmorillonite, Mt, and change the physical and chemical properties of the surface (Torres Sánchez 1997; Dellisanti and Valdré 2005; Hrachová et al. 2007; Fernández et al. 2013; Costa et al. 2013), to obtain diverse low cost products to be used in water treatment or fillers (España et al. 2019; Christidis et al. 2004). Previous studies have demonstrated that the thermal and mechanical treatments alter the framework composition and the structure of Mt mainly by leaching aluminum from the framework and also modifying the negative surface electric charge of the products (Fernández et al. 2013). In addition, both treatments produce a higher particle agglomeration and a total specific surface area (TSSA) decrease. However, because of the interlayer collapse (Torres Sánchez et al. 2011), the external surface value of the products measured by $\mathrm{N}_{2}$ adsorption differ: after a mechanical grinding for $300 \mathrm{~s}$, the surface increased more than twice; instead, for a thermal treatment for $2 \mathrm{~h}$ up to about $600{ }^{\circ} \mathrm{C}$, the area decreased only around $17 \%$. The dissimilar behaviors offer new application alternatives that depend on the external or internal surface sites involved.

Hexavalent chromium, $\mathrm{Cr}(\mathrm{VI})$, is a carcinogen and reproductive toxicant that must be removed from tap water down to safety levels. In aqueous systems, the $\mathrm{Cr}(\mathrm{VI})$ species found are $\mathrm{HCrO}_{4}{ }^{-}, \mathrm{CrO}_{4}{ }^{2-}$, or $\mathrm{Cr}_{2} \mathrm{O}_{7}{ }^{2-}$ anions, which have a high solubility unlike $\mathrm{Cr}(\mathrm{III})$, where the formation of each $\mathrm{Cr}(\mathrm{VI})$ species depends on the $\mathrm{pH}$ and concentration. The adsorption method that uses clays, like Mt, as sorbent material has the benefit of its low cost and easy handling (Uddin 2017) but the negatively charged surface of Mt over a wide range of $\mathrm{pH}$ renders the adsorption of $\mathrm{Cr}(\mathrm{VI})$ anions negligible (Dimos et al. 2012). To improve the adsorption of $\mathrm{Cr}(\mathrm{VI})$ and $\mathrm{Cr}(\mathrm{III})$ surfactants, mixture on $\mathrm{Mt}$ was used (Sarkar et al. 2013). Organo-montmorillonite, OMt, with octadecyl trimethyl ammonium (ODTMA) loading, has been used with diverse results (Qurie et al.
2013; Wang et al. 2016), achieving the highest Cr(VI) adsorption at $\mathrm{pH} 3$ (Thanos et al. 2012).

Because $\mathrm{Cr}(\mathrm{VI})$ sorption on OMt samples occurs mainly at the external surface of the clay system (Bajda and Klapyta 2013), it is desirable to increase this surface before the OMt synthesis. During the OMt preparation, the surfactant is located at the two surface sorption sites of the base Mt: external and internal (or interlayer space) surfaces (Bianchi et al. 2013). Consequently, the increase in the external surface of Mt sample found after the mechanical treatment could also enhance the surfactant amount located at this surface site. For Mt thermally treated at $600{ }^{\circ} \mathrm{C}$, the interlayer collapse originated would also drive the surfactant to the remaining external surface. In addition, the formation of new phases with the application of higher temperature (around $900^{\circ} \mathrm{C}$ ) to the Mt sample (Emmerich et al. 2017) could offer alternative adsorption sites, which to the authors' knowledge have not been investigated yet.

The main purpose of the present study is to optimize the adsorption of $\mathrm{Cr}(\mathrm{VI})$ on an Argentine Mt by driving the ODTMA surfactant loading to the more effective external surface sites through mechanical or thermal treatments. Several techniques have been used to characterize the samples after each step: X-ray diffraction, thermogravimetric analysis, Mössbauer spectroscopy, zeta potential, contact angle, apparent equivalent sphere diameter, and total specific surface area. To determine whether the surface is one of the driving forces of the adsorption, the amount of surfactant loaded at the external surface has been assessed and related to the zeta potential values. The $\mathrm{Cr}(\mathrm{VI})$ retention of products has been determined at two solid/liquid ratios: $1 \mathrm{~g} / \mathrm{L}$ and $5 \mathrm{~g} / \mathrm{L}$.

\section{Materials and Methods}

\subsection{Materials}

The montmorillonite (Mt) sample used in this study was from Río Negro Province, Argentina, delivered by Castiglione Pes y Cia. Mineralogy analysis of Mt indicated that it contained Na-montmorillonite $(>84 \%)$ with quartz, feldspars, and gypsum as impurity. The chemical analysis showed that its chemical structure was $\left[\left(\mathrm{Si}_{3.89} \mathrm{Al}_{0.11}\right)\left(\mathrm{Al}_{1.43} \mathrm{Fe}^{3+}{ }_{0.28} \mathrm{Mg}_{0.30}\right) \mathrm{O}_{10}(\mathrm{OH})_{2}\right] \mathrm{Na}^{+}{ }_{0.41}$ (Magnoli et al. 2008). The cationic exchange capacity (CEC), determined by $\mathrm{Cu}$-triethylenetetramine method, 
was $0.825 \mathrm{mmol} / \mathrm{g}$, the external specific surface area = $34 \mathrm{~m}^{2} / \mathrm{g}$, determined by $\mathrm{N}_{2}$ adsorption, and the isoelectric point 2.7 (Gamba et al. 2015).

The octadecyl trimethyl ammonium bromide (ODTMABr; purity 98\%) was purchased from SigmaAldrich Co. and used as received. The ODTMABr solubility in water is $0.095 \mathrm{~g} / \mathrm{L}$ at $25{ }^{\circ} \mathrm{C}, \mathrm{MW}=$ $392.5 \mathrm{~g} / \mathrm{mol}$, and critical micelle concentrations $(\mathrm{CMC})=3 \times 10^{-4} \mathrm{M}$ (Rosen and Kunjappu 2012). $\mathrm{K}_{2} \mathrm{Cr}_{2} \mathrm{O}_{7}$ and 1,5-diphenylcarbazide were of analytical grade, provided by Sigma-Aldrich Co. (Milwaukee, WI, USA) and used as received.

\subsection{Mechanical and Thermal Treatments}

The Mt was subjected to mechanical treatment in an oscillating mill (Herzog HSM 100), with a rotational frequency of $12.5 \mathrm{~Hz}$ for $300 \mathrm{~s}$; the obtained product was labeled as $\mathrm{Mt}_{300 \mathrm{~s}}$. The thermal treatments on $\mathrm{Mt}$ sample were performed in a furnace (Indef, model 272) at $600{ }^{\circ} \mathrm{C}$ or $950{ }^{\circ} \mathrm{C}$ in air for $2 \mathrm{~h}$, with a heat rate of $10{ }^{\circ} \mathrm{C} / \mathrm{min}$. Solid samples obtained were labeled as $\mathrm{Mt}_{600^{\circ} \mathrm{C}}$ and $\mathrm{Mt}_{950^{\circ} \mathrm{C}}$, respectively. The CEC values for $\mathrm{Mt}_{300 \mathrm{~s}}$ and $\mathrm{Mt}_{600^{\circ} \mathrm{C}}$ samples, determined as indicated previously for Mt sample, were $0.931 \mathrm{mmol} / \mathrm{g}$ clay and $0.638 \mathrm{mmol} / \mathrm{g}$ clay, respectively. This difference in CEC values is due to the different treatmentsthermally or mechanically treated Mt clays - and is consistent with that reported previously (Emmerich et al. 1999; Djukić et al. 2013).

\subsection{ODTMA Loading}

The ODTMA loading on Mt and treated products was performed according to a procedure described previously (Gamba et al. 2015). Briefly, the ODTMABr amount equivalent to 50 or $100 \% \mathrm{CEC}$ value of $\mathrm{Mt}$ was dissolved in $1 \mathrm{~L}$ of distilled water, and $5 \mathrm{~g}$ of each solid sample (raw Mt and its mechanically or thermally treatment products) was slowly added and stirred (400 rpm) for $2 \mathrm{~h}$ at $60{ }^{\circ} \mathrm{C}$. The attained products were washed with distilled water to free them of bromide anions (tested by $\mathrm{AgNO}_{3}$ ) and dried at $80^{\circ} \mathrm{C}$ overnight. The ODTMA-loaded samples were labeled as OMt- $X$, $\mathrm{OMt}_{300 \mathrm{~s}^{-}} X, \mathrm{OMt}_{600^{\circ} \mathrm{C}^{-}} X$, and $\mathrm{OMt}_{950^{\circ} \mathrm{C}^{-}} X$, where $X, 50$, or 100 , indicates the initial percentage of ODTMA used.

\subsection{Methods}

XRD patterns were obtained on powder samples within $3^{\circ}<2 \theta<70^{\circ}$, using Bruker AXS D2 Phaser equipment with $\mathrm{CuK}_{\alpha}$ radiation and a $\mathrm{Ni}$ filter, operated at $40 \mathrm{kV}$ and $35 \mathrm{~mA}$, with counting time of $2.5 \mathrm{~s} / \mathrm{step}$ and $0.04^{\circ}$

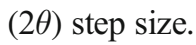

Mössbauer spectra were collected at room temperature (RT) using a constant acceleration spectrometer in transmission geometry $\left({ }^{57} \mathrm{Co} / \mathrm{Rh}\right.$ source and a multichannel scale of 512 channels). Velocity calibration was performed using a $\alpha$-Fe foil (12 $\mu$ m thick). The isomer shift is referred to this standard. Mössbauer spectra of raw $\mathrm{Mt}, \mathrm{Mt}_{300 \mathrm{~s}}$, and $\mathrm{Mt}_{600^{\circ} \mathrm{C}}$ were collected between $\pm 12 \mathrm{~mm} / \mathrm{s}$ and, because no magnetic signal was detected, they were again measured between \pm $4.0 \mathrm{~mm} / \mathrm{s}$. Mössbauer spectrum of $\mathrm{Mt}_{950}{ }^{\circ} \mathrm{C}$ was collected between $\pm 12 \mathrm{~mm} / \mathrm{s}$. All the spectra were numerically analyzed using a commercial program that takes into account hyperfine magnetic fields and quadrupole splitting distributions (Lagarec and Rancourt 1998).

Thermogravimetric analysis (TGA) was conducted using Rigaku TG 8121 Thermo plus EVO2 equipment with alumina as reference. Samples of $20 \mathrm{mg}$ were placed in $\mathrm{Al}_{2} \mathrm{O}_{3}$ crucibles and heated from 30 to $1000{ }^{\circ} \mathrm{C}$ at a scanning rate of $10{ }^{\circ} \mathrm{C} / \mathrm{min}$ in air atmosphere.

Electrophoretic potentials were determined using Brookhaven 90Plus/Bi-MAS with a Multi Angle Particle Sizing Option, operated at $\lambda=635 \mathrm{~nm}$, solid-state laser at $15 \mathrm{~mW}$, scatter angle $=90^{\circ}$, and $25^{\circ} \mathrm{C}$, and employing Pd electrodes. The electrophoretic mobility was converted automatically into zeta potential values using the Smoluchowski equation (Pecini and Avena 2013). To generate the zeta potential versus $\mathrm{pH}$ curves, $40 \mathrm{mg}$ of sample was dispersed in $40 \mathrm{~mL} 10^{-3} \mathrm{M} \mathrm{KCl}$, used as inert electrolyte. The slurry was continuously stirred, and the suspension $\mathrm{pH}$ was adjusted by adding drops of $\mathrm{HCl}$ or $\mathrm{KOH}$ of different concentrations until equilibrium was attained (10 $\mathrm{min})$.

The contact angle (CA) was determined by the procedure indicated previously (Orta et al. 2019). Briefly, sample $(0.5 \mathrm{~g})$ was pressed in a disc shape of $150-\mathrm{mm}$ diameter using uniaxial pressure $(34.3 \mathrm{MPa})$; it was sanded to smooth out the roughness of the surface, and the sessile drop method was used to determine the CA. A drop of deionized water $(V=30 \mu \mathrm{L})$ was placed on the sample and after $30 \mathrm{~ms}$; when the mechanical perturbations ended, the CA was measured using the 
photographic camera of the L74PT1600 Linseis thermal microscope at room temperature. The images were analyzed with a plug-in (Stalder et al. 2010) for the opensource software ImageJ V. 1.46r (Rasband 1997). The accuracy of the method used to determine CA in this work was verified by the $\mathrm{CA}$ value of $57^{\circ}$ obtained for the Mt sample, which is close to that reported for a reference Mt and obtained with a commercial CA microscope (Schampera et al. 2016).

The apparent equivalent sphere diameter (Dapp) was obtained by dynamic light scattering (DLS) measurements using a Brookhaven 90Plus/Bi-MAS with the Multi Angle Particle Sizing Option, which was operated at $\lambda=635 \mathrm{~nm}$ with a $15-\mathrm{mW}$ solid-state laser, scattering angle of $90^{\circ}$, and a temperature of $25 \pm 0.1{ }^{\circ} \mathrm{C}$. All sample suspensions $(1 \% \mathrm{w} / \mathrm{w})$ were prepared using $10^{-3} \mathrm{M} \mathrm{KCl}$ solutions and sonicated for $5 \mathrm{~min}$. The particle size determinations were conducted afterwards.

The total specific surface area (TSSA) was determined from water vapor adsorption at a relative humidity of 0.56, as described elsewhere (Torres Sánchez and Falasca 1997). This method was preferred to the determination of the specific surface area (SSA) by nitrogen adsorption, because, as described previously (Orta et al. 2019), the use of nitrogen as probe molecule produces an underestimation of the SSA of swelling clays, allowing only the determination of the external specific surface area of the clay.

\subsection{Removal Efficiency of $\mathrm{Cr}(\mathrm{VI})$}

The Cr(VI) removal efficiency of raw and modified samples was evaluated in batch system. Solid samples were placed in contact with $50 \mathrm{mg} / \mathrm{L} \mathrm{Cr}(\mathrm{VI})$ solution, at $\mathrm{pH} 3$ and solid/liquid ratios of $1 \mathrm{~g} / \mathrm{L}$ and $5 \mathrm{~g} / \mathrm{L}$. The suspensions were magnetically stirred inside a refrigerated incubator (Forma Scientific, model \#11) for $24 \mathrm{~h}$ at $25^{\circ} \mathrm{C}$, to ensure that the equilibrium was reached (Dultz et al. 2012). Due to the possible $\mathrm{Cr}(\mathrm{VI})$ photoreduction in acidic conditions (S. L. Wang et al. 2009), all the adsorption experiences were performed in darkness. Solid samples were separated by filtration (cellulose nitrate membrane-micromolar $0.22 \mu \mathrm{m}$ ).

The $\mathrm{Cr}(\mathrm{VI})$ equilibrium concentration $\left(C_{\mathrm{e}}\right)$ in the supernatant was determined using a UV/Vis spectrophotometer (Agilent HP-8453) by the diphenylcarbazide method at $\lambda=540 \mathrm{~nm}$ (Clescerl et al. 1998). Briefly, an aliquot volume of supernatant was acidified with $0.5 \mathrm{~mL}$ of $1 \mathrm{M} \mathrm{HNO}_{3}(65 \%$-Anedra) and diluted with water to $10 \mathrm{~mL}$ in a glass flask; $0.5 \mathrm{~mL}$ of the color developing reagent was used $(50 \mathrm{mg}$ of $1,5-$ diphenylcarbazide (DPC) in $10 \mathrm{~mL}$ of acetone AGBiopack). The linear range of $\mathrm{Cr}(\mathrm{VI})$ concentrations versus absorbance was between 0 and $1.0 \mathrm{mg} / \mathrm{L}$, with $R^{2}=0.999$. Total chromium concentration $\left(\mathrm{Cr}_{\mathrm{Total}}\right)$ in solution was determined by using a flame atomic absorption spectrometer (FAAS) (Sens AA dual GBC Scientific Equipment). The parameters required for $\mathrm{Cr}_{\text {Total }}$ analysis were as follows: $\lambda=357.9 \mathrm{~nm}$, current of $6.0 \mathrm{~mA}$, slit $0.2 \mathrm{~nm}$, and air:fuel ratio of $6: 2$. Possible differences between $\mathrm{Cr}_{\text {Total }}$ and $\mathrm{Cr}(\mathrm{VI})$ were considered as $\mathrm{Cr}(\mathrm{III})$.

The removal efficiency of $\mathrm{Cr}(\mathrm{VI})$ adsorbed amount, $Q_{\mathrm{e}}$ (mg Cr/g adsorbent), was determined by:

$\operatorname{Removal}(\%)=\frac{\left(C_{o}-C_{e}\right)}{C_{0}} \times 100$

where $C_{\mathrm{o}}$ and $C_{\mathrm{e}}$ are the initial and the equilibrium concentrations of $\mathrm{Cr}(\mathrm{mg} / \mathrm{L})$, respectively.

\section{Results and Discussion}

\subsection{X-ray Diffraction}

Figure 1 shows the XRD patterns of raw Mt sample and its mechanical or thermal treatment products.

The $\mathrm{Mt}_{600^{\circ} \mathrm{C}}$ sample followed the general behavior attained by dioctahedral TOT clay minerals andthermal dehydroxylation with preservation of the layer structure (Fig. 1) (Schoonheydt et al. 2018). The d001 basal space decrease from $1.27 \mathrm{~nm}$ for $\mathrm{Mt}$ to $0.98 \mathrm{~nm}$ for $\mathrm{Mt}_{600^{\circ} \mathrm{C}}$, as indicated in Fig. 1.

When the temperature for sample treatment was $950{ }^{\circ} \mathrm{C}$, the disappearance of the peak corresponding to 001 and $060\left(62^{\circ}\right.$ of $\left.2 \theta\right)$ signals indicated the destruction of the Mt layer structure. The hydroxyls in the octahedral sheets are dehydrated and all 6-coordinated aluminum becomes 4-coordinated aluminum, producing cristobalite and spinel structures, revealed by the presence of diffraction peaks at 0.41 and $0.25 \mathrm{~nm}$, and the peaks at $0.27,0.26$, and $0.22 \mathrm{~nm}$, respectively (Emmerich et al. 2017; Martignago et al. 2006).

The mechanical treatment $\left(\mathrm{Mt}_{300 \mathrm{~s}}\right)$ originated the widening of $\mathrm{d} 001$ peak that was assigned to the delamination process and reduction of the lamellar and particle size with formation of smaller crystalline domains 
Fig. 1 XRD patterns for indicated samples. Letters indicate the following: G gypsum, Mt montmorillonite, Q quartz, C cristobalite, $\mathrm{S}$ spinel, $\mathrm{H}$ hematite, and $\mathrm{F}$ feldspar. The $Y$-axis for $\mathrm{Mt}_{950^{\circ} \mathrm{C}}$ was augmented $2 \times$ with respect to the other samples. Basal space values are expressed in $\mathrm{nm}$

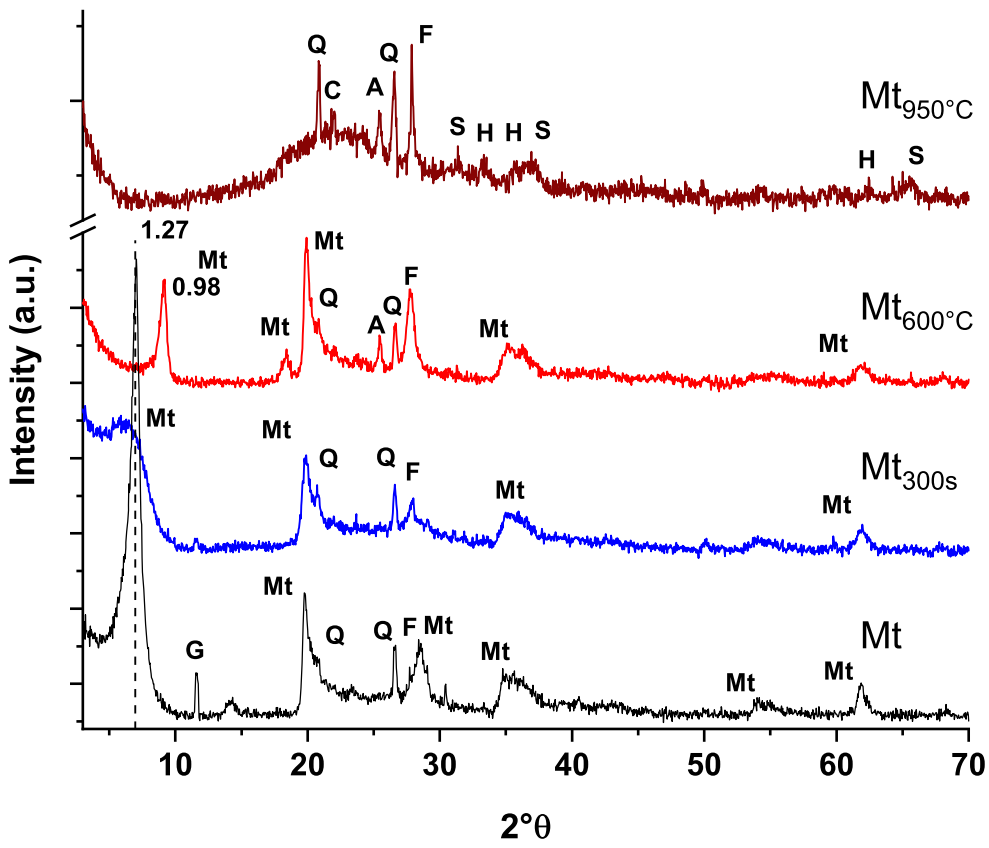

(Pérez-Rodríguez 2003). Also, an intensity loss of the d060 peak indicated a certain degradation of the initial Mt structure, being lower compared with that obtained for the $\mathrm{Mt}_{950^{\circ} \mathrm{C}}$ sample.

For OMt samples, the peak associated with the d001 plane shifted to lower theta angles with the amount of ODTMA loading (Fig. 2a), revealing the surfactant incorporation in the Mt interlayer space. The interlayer space of all samples, determined by subtracting the space of dehydrated Mt $(0.97 \mathrm{~nm})$ from the 001 value, indicated a lateral monolayer arrangement of ODTMA for OMt-50 sample and a pseudotrilayer or a paraffinlike monomolecular one for OMt-100 sample ( 0.48 and $0.92 \mathrm{~nm}$, respectively) consistent with previous data (Gamba et al. 2015; Orta et al. 2019). The d001 peak deconvolution for OMt-50 sample (insets in Fig. 2a), with $R^{2}>0.996$, indicated the existence of two overlapping peaks centered at 1.45 and $1.67 \mathrm{~nm}$. These values correspond to an interlayer increase of 0.48 and $0.70 \mathrm{~nm}$, respectively, and were assigned previously as hydrated remnant $\mathrm{Ca}^{2+}$ and lateral monolayer arrangement of the surfactant, respectively (Orta et al. 2019). However, for OMt-100 sample, the interlayer space width of 0.99 and $0.93 \mathrm{~nm}$ indicated a pseudotrilayer or a paraffin-like monomolecular arrangement of the surfactant with different tilt angles (Bianchi et al. 2013).

When ODTMA was loaded into the $\mathrm{Mt}_{300 \mathrm{~s}}$ sample (Fig. 2b), the intensity of d001 peak increase indicated a more crystalline structure than that of $\mathrm{Mt}_{300 \mathrm{~s}}$ sample. Besides, similar shifts of these peaks to that found for OMt samples were indicative of close surfactant arrangements within these samples. The similar value of the 001 peak mathematical deconvolution, at $1.49 \mathrm{~nm}$, found for $\mathrm{OMt}_{300 \mathrm{~s}}-50$ sample (inset in Fig. 2b) and for OMt-50 sample, it indicated that despite the destruction of the layer structure, some hydrated $\mathrm{Ca}^{2+}$ still remained in $\mathrm{OMt}_{300 \mathrm{~s}}-50$ sample. The value of the $\mathrm{d} 001$ peak deconvolution for $\mathrm{OMt}_{300 \mathrm{~s}}-100$ sample stayed close to that of OMt-100 sample, validating the paraffin-like monomolecular arrangement of the surfactant in both samples.

For the $\mathrm{Mt}_{600^{\circ} \mathrm{C}}$ sample (Fig. 2c), a 50\% CEC of surfactant loading reversed the previous collapse of the basal space, shifting the d001 from $0.98 \mathrm{~nm}$ to $1.82 \mathrm{~nm}$. However, the value of the 001 peak deconvolution indicated the presence of both monolayer (with interlayer space width $=0.65 \mathrm{~nm}$ ) and pseudotrilayer $(0.95 \mathrm{~nm})$ surfactant arrangements, whereas for $\mathrm{Mt}_{600^{\circ}} \mathrm{C}^{-100}$ sample (inset in Fig. 2c), the surfactant attained bilayer and pseudotrilayer arrangements, with interlayer space width of 0.76 and $0.90 \mathrm{~nm}$, respectively.

Particularly for $\mathrm{Mt}_{950^{\circ} \mathrm{C}}$ sample, the destruction of the Mt layer structure was irreversible (Fig. S1, Online Resource 1), showing low surfactant loading, as will be shown in Section 3.3. 

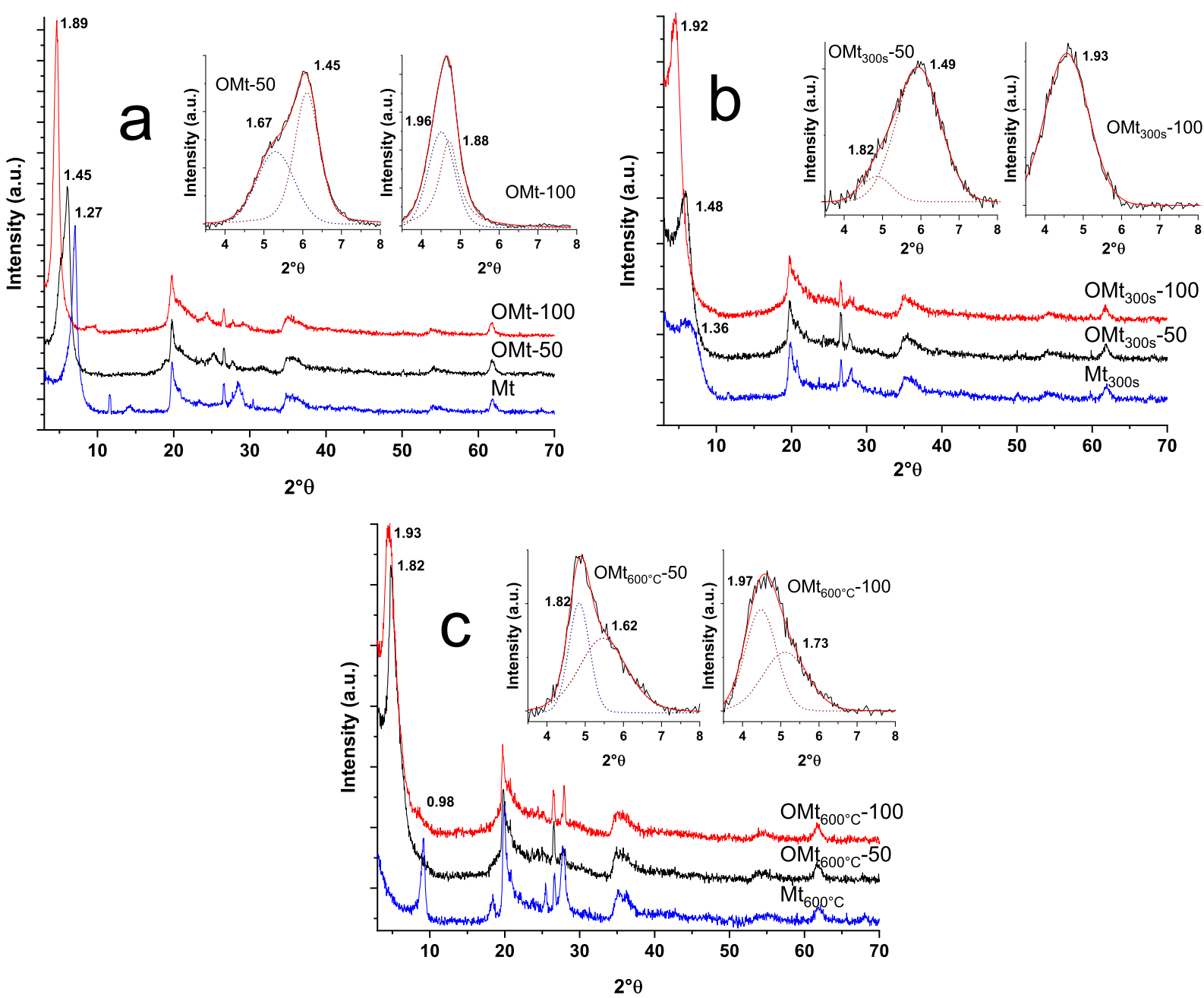

Fig. 2 XRD patterns for a Mt and its surfactant-loaded products, b $\mathrm{Mt}_{300 \mathrm{~s}}$ and surfactant-loaded products, and $\mathbf{c} \mathrm{Mt}_{600^{\circ} \mathrm{C}}$ and surfactant-loaded products. The insets depict the deconvolution

The comparison of the shape of d001 peaks, for samples with the same \% CEC exchange without and with different treatments (Fig. S2, Online Resource 1), revealed higher crystallinity and larger crystalline domains for $\mathrm{OMt}-50$ and $\mathrm{OMt}_{600^{\circ} \mathrm{C}}-50$ samples. However, the decrease in the d001 peak and distortions in the crystalline domains found for $\mathrm{OMt}_{300 \mathrm{~s}}-50$ sample with respect to other surfactant-loaded samples indicated that the delamination process still remained.

\subsection{Mössbauer Spectroscopy}

In order to determine the existence of structural $\mathrm{Fe}^{2+}$ to neglect the possible reduction of $\mathrm{Cr}(\mathrm{VI})$, Mössbauer spectroscopy was used. Mössbauer spectra disclosed of d001 peaks for surfactant samples loaded at 50 and $100 \%$ CEC. Basal space values are expressed in $\mathrm{nm}$

different Fe environments in the clay samples. Table 1 displays the hyperfine parameters of each identified environment.

Mt and $\mathrm{Mt}_{300 \text { s }}$ spectra were fitted considering two sites, whose hyperfine parameters are consistent with those expected for $\mathrm{Fe}^{3+}$ at the octahedral environments of the Mt structure (Johnston and Cardile 1987), in addition to a paramagnetic relaxation caused by the $\mathrm{Mt}$ relatively low $\mathrm{Fe}$ concentration (Murad and Cashion 2004). Mössbauer spectra of $\mathrm{Mt}$ and $\mathrm{Mt}_{300 \text { s }}$ samples did not differ greatly; i.e., the grinding process did not change significantly change the Fe environments of the Mt sample.

The spectra of the samples after the firing process showed considerable changes, as was observed for other 
Mt samples (Murad and Cashion 2004), that exhibited an increase in the quadrupole splitting of $\mathrm{Fe}^{3+}$ environments.

Considering both the X-ray diffraction (Section 3.1) and Mössbauer spectroscopy results, it can be suggested that for the $\mathrm{Mt}_{600^{\circ} \mathrm{C}}$ sample, whose crystalline structure did not change significantly, part of the thermal energy was transferred to the $\mathrm{Fe}^{3+}$ ions located in the octahedral sites, promoting the rejection of the atoms and disturbing the site geometry. For the $\mathrm{Mt}_{950^{\circ} \mathrm{C}}$ sample (the Mt structure is not conserved), the octahedral sites may now belong to a spinel structure (revealed by the XRD patterns in paragraphs below), where the $\mathrm{Fe}^{3+}$ ions replace the $\mathrm{Al}$ ones, forming the spinel $\mathrm{FeAlO}_{4}$. In parts of this sample, the transferred thermal energy was enough to produce the total $\mathrm{Al}$ replacement, bringing about hematite $\mathrm{Fe}_{2} \mathrm{O}_{3}$ formation.

Within experimental uncertainties, in no sample, the presence of $\mathrm{Fe}^{2+}$ was detected. This discards a $\mathrm{Cr}(\mathrm{VI})$ possible oxide reduction process. Summing up, it seems that the grinding process did not significantly affect the Fe environments of Mt sample, in contrast to the thermal treatments in which intermediate compounds $\left(\mathrm{Mt}_{600}{ }^{\circ} \mathrm{C}\right)$ or hematite formation $\left(\mathrm{Mt}_{950^{\circ} \mathrm{C}}\right)$ can be identified.

\subsection{Thermogravimetric Analysis}

The thermogravimetric analysis was performed on the Mt and its thermal and mechanical products without and with ODTMA loading to evaluate the surfactant incorporation and to determine the actual loading with respect to the respective base Mt \% CEC.

The thermal decomposition of $\mathrm{Mt}_{950^{\circ} \mathrm{C}}$ sample is not presented because its low mass loss $(<1 \%)$ over the entire analyzed temperature range is within the method error (Fig. S3, Online Resource 1).

The thermal decomposition of Mt and its thermal and mechanical products was analyzed in three temperature ranges $<150{ }^{\circ} \mathrm{C}, 150-500{ }^{\circ} \mathrm{C}$, and $>500{ }^{\circ} \mathrm{C}$ (Fig. 3) (Orta et al. 2019). The dehydration process of adsorbed water at temperature $<150{ }^{\circ} \mathrm{C}$ decreased from $14.3 \%$ for Mt to $12.2 \%$ and $2.5 \%$ for $\mathrm{Mt}_{300 \mathrm{~s}}$ and $\mathrm{Mt}_{600}{ }^{\circ} \mathrm{C}$ samples, respectively (Table 2), in agreement with the intensity decrease of the $\mathrm{d} 001$ peaks of the latter samples, as was indicated in Section 3.1 (Fig. 1). The mass loss in the $150-500{ }^{\circ} \mathrm{C}$ range was assigned to surfactant decomposition (Hedley et al. 2007), and consequently, for these three samples, a low mass loss was expected $(\leq 2.8 \%)$. In the $500-1000{ }^{\circ} \mathrm{C}$ range, a mass loss of up to $4.4 \%$ was assigned to the loss of the Mt structural hydroxyl groups. In this temperature range, the shift to lower temperature from $663{ }^{\circ} \mathrm{C}$ for $\mathrm{Mt}$ to $616^{\circ} \mathrm{C}$ and $476{ }^{\circ} \mathrm{C}$ for $\mathrm{Mt}_{300 \mathrm{~s}}$ and $\mathrm{Mt}_{600}{ }^{\circ} \mathrm{C}$ samples, respectively (Fig. 3), is noteworthy. The dehydroxylation temperature decrease for mechanical treated sample $\left(\mathrm{Mt}_{300 \mathrm{~s}}\right)$ was assigned previously to the creation of new edge planes that favored the dehydroxylation of the samples (Fernández et al. 2013), while for thermal treated sample $\left(\mathrm{Mt}_{600^{\circ} \mathrm{C}}\right)$ this behavior could be assigned to a rehydroxylation after the thermal treatment (Emmerich et al. 1999).

For ODTMA-loaded samples, the dehydration temperature showed an important intensity decrease and a shift to lower temperatures (around $30^{\circ} \mathrm{C}$ ) with respect to the corresponding treated base samples (Fig. 4a, b), indicative of the hydrated interlayer cations exchanged by the surfactant (Orta et al. 2019).

The organic cation decomposition was evidenced by the presence of peaks within $150-500{ }^{\circ} \mathrm{C}$ (Hedley et al. 2007), where the surfactant loading increase shifted the respective peak to lower temperatures, besides widening them. In $\mathrm{OMt}_{600^{\circ} \mathrm{C}}-100$ sample, the presence of a shoulder can also be observed.

These changes in the shape of the DTGA peaks with the surfactant loading increase validate the occurrence of stronger interactions of the cation exchange process at higher temperatures (around $300^{\circ} \mathrm{C}$ ) and Van der Waals (VdW) interactions between the long tails of the adsorbed surfactant at the Mt surface at lower temperatures (around $260^{\circ} \mathrm{C}$ ) (Orta et al. 2019).

In previous work, the mathematical deconvolution of the abovementioned DTGA peaks allowed determining the percentage of both interaction mechanisms (Orta et al. 2019). The mass loss values of the Mt and treated samples, and their products loaded with ODTMA, are summarized in Table 2. The peak areas within 150$500{ }^{\circ} \mathrm{C}$ were used to determine the actual surfactant loaded, and the mathematical deconvolution of these peaks (Fig. S4, Online Resource 1) allowed determining the surfactant amount assigned to $\mathrm{VdW}$ or cation exchange processes. With the purpose of comparing the values obtained in each process, the unit areas obtained are referred to as \% CEC of the respective base sample.

The different $\mathrm{CEC}$ values found for $\mathrm{Mt}_{300 \mathrm{~s}}$ and $\mathrm{Mt}_{600^{\circ} \mathrm{C}}$ samples with respect to $\mathrm{Mt}(0.931 \mathrm{mmol} / \mathrm{g}$ and $0.638 \mathrm{mmol} / \mathrm{g}$, respectively) generated the decrease or the increase of the actual surfactant-loaded percentage for the respective surfactant-loaded samples, compared with OMt-50 and OMt-100 samples (Table 2). It is 
Table 1 Mössbauer hyperfine parameters of the samples on the leftmost columns. $\delta$ and $\Delta$ stand for the isomer shift and the quadrupole splitting in mm/s, respectively. $H$ is the hyperfine magnetic field in T. RSA $(\%)$ is the relative percentage of the spectral area of each Fe phase

\begin{tabular}{|c|c|c|c|c|c|c|c|c|c|c|c|c|c|}
\hline \multirow[t]{2}{*}{ Sample } & \multicolumn{3}{|l|}{$\mathrm{Fe}^{3+}(\mathrm{I})$} & \multicolumn{3}{|l|}{$\mathrm{Fe}^{3+}(\mathrm{II})$} & \multicolumn{3}{|l|}{$\mathrm{Fe}^{3+}(\mathrm{III})$} & \multicolumn{4}{|l|}{$\mathrm{Fe}_{2} \mathrm{O}_{3}$} \\
\hline & $\begin{array}{l}\delta \\
(\mathrm{mm} / \mathrm{s})\end{array}$ & $\begin{array}{l}\Delta \\
(\mathrm{mm} / \mathrm{s})\end{array}$ & $\begin{array}{l}\text { RSA } \\
(\%)\end{array}$ & $\begin{array}{l}\delta \\
(\mathrm{mm} / \mathrm{s})\end{array}$ & $\begin{array}{l}\Delta \\
(\mathrm{mm} / \mathrm{s})\end{array}$ & $\begin{array}{l}\text { RSA } \\
(\%)\end{array}$ & $\begin{array}{l}\delta \\
(\mathrm{mm} / \mathrm{s})\end{array}$ & $\begin{array}{l}\Delta \\
(\mathrm{mm} / \mathrm{s}\end{array}$ & $\begin{array}{l}\text { RSA } \\
(\%)\end{array}$ & $\begin{array}{l}\delta \\
(\mathrm{mm} / \mathrm{s})\end{array}$ & $\begin{array}{l}\varepsilon \\
(\mathrm{mm} / \mathrm{s})\end{array}$ & $\begin{array}{l}H \\
(\mathrm{~T})\end{array}$ & $\begin{array}{l}\text { RSA } \\
(\%)\end{array}$ \\
\hline $\mathrm{Mt}$ & 0.36 & 0.50 & $50 \pm 6$ & 0.37 & 1.03 & $28 \pm 5$ & 0.45 & 0.01 & $22 \pm 4$ & - & - & - & - \\
\hline $\mathrm{Mt}_{300 \mathrm{~s}}$ & 0.36 & 0.53 & $49 \pm 6$ & 0.39 & 1.06 & $24 \pm 5$ & 0.35 & 0.48 & $28 \pm 4$ & - & - & - & - \\
\hline $\mathrm{Mt}_{600^{\circ} \mathrm{C}}$ & 0.37 & 0.68 & $23 \pm 4$ & 0.37 & 1.36 & $60 \pm 5$ & 0.38 & 2.37 & $17 \pm 4$ & - & - & - & - \\
\hline $\mathrm{Mt}_{950^{\circ} \mathrm{C}}$ & 0.34 & 0.65 & $42 \pm 5$ & 0.31 & 1.10 & $38 \pm 5$ & - & - & - & 0.35 & -0.11 & 50.2 & $20 \pm 4$ \\
\hline
\end{tabular}

important to note that while the surfactant percentage assigned to the cation exchange mechanism does not vary considerably within both surfactant-loaded samples (without and with treatments), the corresponding percentage to the surfactant assigned to VdW mechanism increased more than twice for $100 \%$ with respect to the initial 50\% surfactant-loaded samples.

The increase in mass loss observed in the temperature range between 500 and $1000{ }^{\circ} \mathrm{C}$ for all the organic loaded samples was assigned not only to the dehydroxylation but also to carbon loss, produced by the combustion of the organic found in the interlaminar space (Yariv 2001).

\subsection{Zeta Potential Measurements}

The surface electric charge of the montmorillonite, evaluated by zeta potential measurements, was determined by the permanent negative charge on the face and by the edge charge that changes from negative to positive with decreasing $\mathrm{pH}$. The predominance of negative charges on the faces of particles compared with the positive charge on the edges generates a negative net charge in all the investigated $\mathrm{pH}$ values (Missana and Adell 2000), as shown in Fig. 5.

For $\mathrm{Mt}_{300 \mathrm{~s}}$ and $\mathrm{Mt}_{600^{\circ} \mathrm{C}}$ samples, the negative surface charge decrease with respect to the Mt sample was assigned previously to the following behavior: (a) some aluminum release into the solution, (b) the enrichment of aluminum ions or hydroxo-aluminum species at the edges and/or the face (+) edge (-) contacts, and (c) the migration of $\mathrm{Al}$ cations from the original trans-octahedral sites to formerly unoccupied fivefold prisms (Torres Sánchez et al. 2011). For $\mathrm{Mt}_{300 \text { s }}$ and $\mathrm{Mt}_{600{ }^{\circ} \mathrm{C}}$ samples, a higher decrease of the negative zeta potential values was found for the first sample with respect to the thermally treated one. This behavior can be assigned to the different structure alterations within
Fig. 3 TGA and DTGA curves for indicated samples: Mt (solid line), $\mathrm{Mt}_{600^{\circ} \mathrm{C}}$ (dotted line), and $\mathrm{Mt}_{300 \mathrm{~s}}$ (dashed line) samples

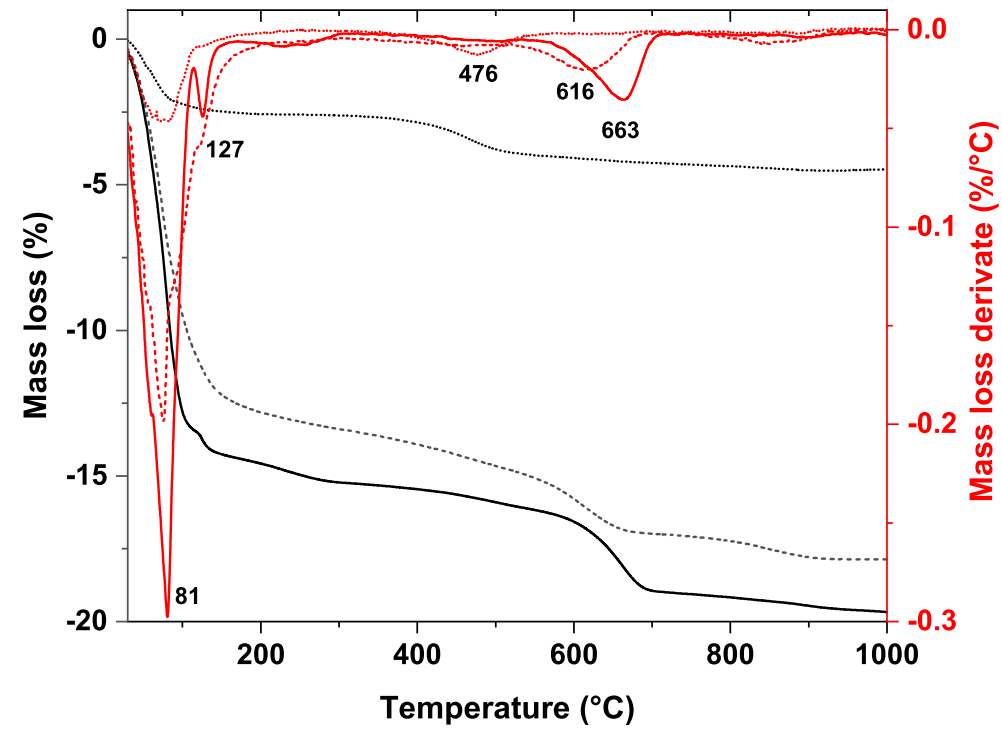


Table 2 Mass loss percentage of $\mathrm{Mt}, \mathrm{Mt}_{300 \mathrm{~s}}$, and $\mathrm{Mt}_{600^{\circ} \mathrm{C}}$ and the respective ODTMA-loaded samples, the total actual surfactant loaded, surfactant assigned to $\mathrm{VdW}$ and cation exchange processes expressed as \% CEC of the respective base sample, and $R^{2}$ indicate the fit of the respective mathematical deconvolution

\begin{tabular}{|c|c|c|c|c|c|c|c|}
\hline \multirow[t]{2}{*}{ Sample } & \multicolumn{3}{|c|}{ Mass loss (\%) } & \multirow{2}{*}{$\begin{array}{l}\text { Total actual surfactant } \\
\text { loaded (\% CEC) }\end{array}$} & \multirow{2}{*}{$\begin{array}{l}\text { Surfactant assigned } \\
\text { to VdW (\% CEC) }\end{array}$} & \multirow{2}{*}{$\begin{array}{l}\text { Surfactant assigned to } \\
\text { cation exchange (\% CEC) }\end{array}$} & \multirow[t]{2}{*}{$R^{2}$} \\
\hline & $\begin{array}{l}25-150 \\
\left({ }^{\circ} \mathrm{C}\right)\end{array}$ & $\begin{array}{l}150-500 \\
\left({ }^{\circ} \mathrm{C}\right)\end{array}$ & $\begin{array}{l}500-1000 \\
\left({ }^{\circ} \mathrm{C}\right)\end{array}$ & & & & \\
\hline $\mathrm{Mt}$ & 14.3 & 1.9 & 4.4 & - & - & - & - \\
\hline OMt-50 & 4.6 & 8.3 & 9.9 & 49 & 18 & 31 & 0.995 \\
\hline OMt-100 & 2.5 & 16.6 & 11.6 & 91 & 59 & 32 & 0.983 \\
\hline $\mathrm{Mt}_{300 \mathrm{~s}}$ & 12.2 & 2.8 & 3.7 & - & - & - & - \\
\hline $\mathrm{OMt}_{300 \mathrm{~s}}-50$ & 7.1 & 9.7 & 8.2 & 42 & 21 & 21 & 0.990 \\
\hline $\mathrm{OMt}_{300 \mathrm{~s}}-100$ & 4.4 & 18.0 & 9.9 & 79 & 58 & 20 & 0.995 \\
\hline $\mathrm{Mt}_{600^{\circ} \mathrm{C}}$ & 2.5 & 1.3 & 0.7 & - & - & - & - \\
\hline $\mathrm{OMt}_{600^{\circ} \mathrm{C}^{-}}-50$ & 1.7 & 8.0 & 5.7 & 59 & 32 & 28 & 0.990 \\
\hline $\mathrm{OMt}_{600^{\circ} \mathrm{C}^{-100}}$ & 2.3 & 16.5 & 6.0 & 105 & 79 & 26 & 0.997 \\
\hline
\end{tabular}

both treatments, which could generate more exposed edge sites after mechanical than after thermal treatments. The positive charge up to $\mathrm{pH}$ around 7 of the Mt edge sites (Pecini and Avena 2013) reduces the negative zeta potential value of the Mt sample. Besides, the delamination of $\mathrm{Mt}_{300 \mathrm{~s}}$ sample, evidenced in the XRD section, could also contribute to the decrease of the negative zeta potential values with respect to those of $\mathrm{Mt}_{600^{\circ} \mathrm{C}}$ sample.

For the $\mathrm{Mt}_{950^{\circ} \mathrm{C}}$ sample, in addition to the above considerations, the presence of cristobalite (XRD), whose isoelectric point is located at pH 2.5 (Júnior and Baldo 2014), could contribute to the decrease of zeta potential values with respect to those of Mt sample.
The microelectrophoresis method evaluates only the changes in the external surface, which is important for the analysis of Mt samples with loaded surfactant, since the neutrality of the interlayer is maintained despite the exchange of cations produced, e.g., by surfactant loading (Thomas et al. 1999).

The ODTMA loading in Mt (Fig. 6) produced a decrease of the negative zeta potential value of approximately $10 \mathrm{mV}$ for the OMt-50 sample and a reversal to a positive zeta potential value of up to $30 \mathrm{mV}$ for OMt100 sample, according to our previous results (Bianchi et al. 2013; Orta et al. 2019). Particularly, the positive zeta potential value found for the OMt-100 sample was assigned to the increase of the surfactant coverage at the
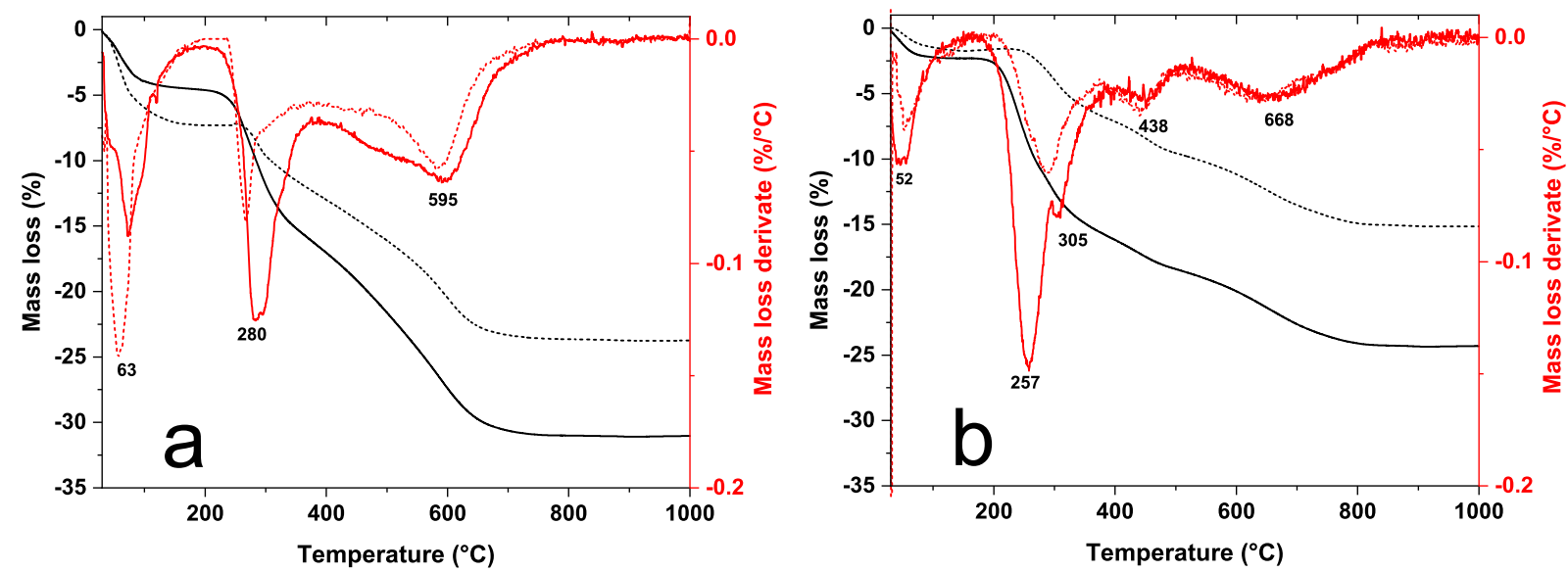

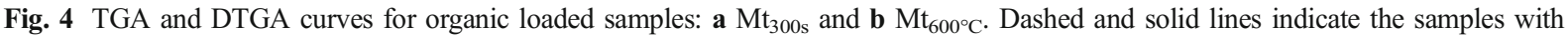
surfactant loaded at 50 and $100 \%$ CEC, respectively 
Fig. 5 Zeta potential versus $\mathrm{pH}$ curves of (square) Mt, (circle) $\mathrm{Mt}_{300 \text { s }}$, and (up triangle) $\mathrm{Mt}_{600^{\circ} \mathrm{C}}$ and (down triangle) $\mathrm{Mt}_{950^{\circ} \mathrm{C}}$ samples

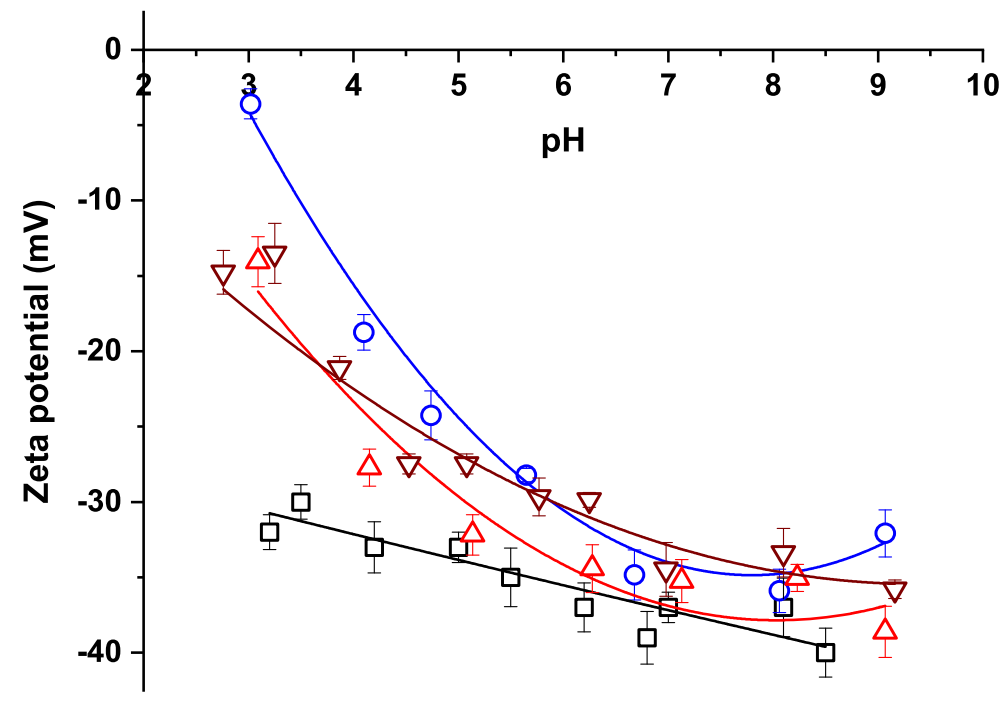

external surface and the arrangement of the ammonium group in head-tail orientation, as happened for hexadecyl trimethyl ammonium (Praus et al. 2006).

The surface coverage of $\mathrm{Mt}_{300 \mathrm{~s}}$ sample by the two amounts of surfactant $\left(\mathrm{OMt}_{300 \mathrm{~s}} \mathrm{~s}-50\right.$ and $\mathrm{OMt}_{300 \mathrm{~s}}-100$ samples), although their total actual surfactant loads were close to those obtained for the OMt samples (Table 2), generated lower negative zeta potential values than those found for the respective OMt samples.

The differences in zeta potential values for $\mathrm{OMt}_{300 \mathrm{~s}}{ }^{-}$ 50 and $\mathrm{OMt}_{300 \mathrm{~s}}-100$ samples with respect to $\mathrm{Mt}_{300 \mathrm{~s}}$ sample were around $5 \mathrm{mV}$ and $20 \mathrm{mV}$, respectively, while these differences for OMt-50 and OMt-100 samples with respect to Mt sample were around $10 \mathrm{mV}$ and $65 \mathrm{mV}$, respectively.

This zeta potential value behavior would indicate that the amount of surfactant at the external surface was lower for the mechanically treated than for Mt samples. However, the amount of surfactant assigned to VdW interactions for the $\mathrm{OMt}_{300 \mathrm{~s}} \mathrm{~s}-50$ and $\mathrm{OMt}_{300 \mathrm{~s}}-100$ samples was similar to that of the respective OMt samples (Table 2), which seems to contradict the previous assumption.

Consequently, this behavior could be assigned to a higher surface development of $\mathrm{OMt}_{300 \mathrm{~s}}-50$ and $\mathrm{OMt}_{300 \mathrm{~s}}-100$ samples than that of the respective $\mathrm{OMt}$ samples. Although the $\mathrm{OMt}_{300 \mathrm{~s}^{-}}-100$ sample has a percentage of surfactant (Table 2) exchanged by VdW mechanism similar to that of OMt-100 sample, the higher surface of the former sample, as will be shown in Table 3 , is a consequence of the delamination process.
Moreover, the existence of smaller crystalline domains, previously specified in the XRD section, generated the smaller increase in the positive zeta potential value found for $\mathrm{OMt}_{300 \mathrm{~s}}-100$ than for the OMt-100 sample with respect to their respective initial samples (samples $\mathrm{Mt}_{300 \mathrm{~s}}$ and $\mathrm{Mt}$ ).

For $\mathrm{Mt}_{600^{\circ} \mathrm{C}}$ sample, greater actual ODTMA amounts than those of Mt sample (Table 2) produced a decrease of negative zeta potential values from around -25 to $30 \mathrm{mV}$ for $\mathrm{OMt}_{600^{\circ} \mathrm{C}^{-}} 50$ sample with respect to $\mathrm{Mt}_{600^{\circ} \mathrm{C}}$ sample (Figs. 5 and 6), while differences up to $35 \mathrm{mV}$ were attained for $\mathrm{OMt}_{600}{ }^{\circ} \mathrm{C}^{-100}$ sample (Fig. 6). The higher decrease of negative zeta potential values obtained for $\mathrm{OMt}_{600}{ }^{\circ} \mathrm{C}^{-50}$ than for OMt-50 sample validates the greater amount of surfactant interacting by the VdW mechanism in the first sample (Table 2) and/or the decrease of the surface in thermally treated sample (Table 3). The similar zeta potential value found for $\mathrm{OMt}_{600} \mathrm{C}^{-}-100$ and OMt-100 samples, when a higher amount of surfactant interacted by the VdW mechanism in the first sample (Table 2), would indicate that, besides the head-tail orientation of the surfactant at higher concentrations, mixed micelles were formed in bulk solution (Zhang et al. 2012), not allowing a further increase in the zeta potential value.

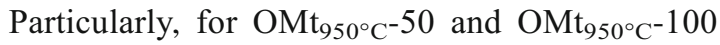
samples, the zeta potential values (Fig. 6) remained close to those obtained for $\mathrm{Mt}_{950^{\circ} \mathrm{C}}$ sample (Fig. 5), which validates the almost-null surfactant adsorption revealed by DTGA. 
Fig. 6 Zeta potential versus $\mathrm{pH}$ curves of $\mathrm{Mt}$ (square), $\mathrm{Mt}_{300 \text { s }}$ (circle), $\mathrm{Mt}_{600{ }^{\circ} \mathrm{C}}$ (up triangle) and $\mathrm{Mt}_{950^{\circ} \mathrm{C}}$ (down triangle) samples. Symbols indicated the following: (half full) with 50 and (full) with $100 \%$ CEC

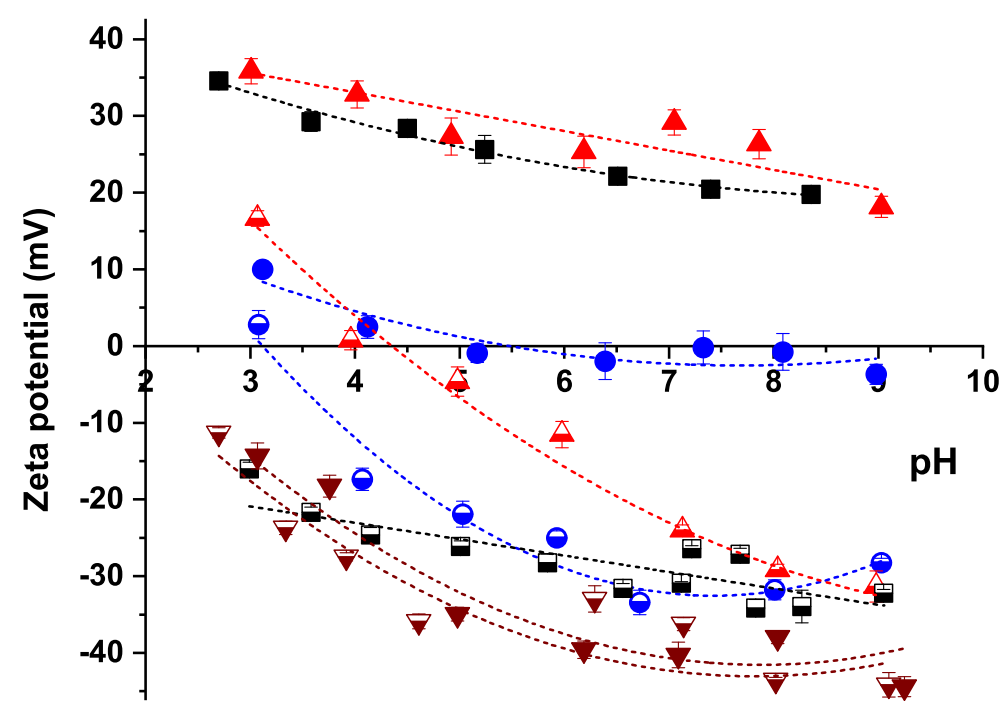

Summing up, in a first approach, zeta potential results showed that surfactant loading in mechanically treated samples attained a lower relative decrease of negative zeta potential values than that of OMt samples. Meanwhile, in raw and thermally treated samples $\left(\mathrm{Mt}_{600^{\circ} \mathrm{C}}\right.$ samples), the decrease of negative zeta potential values after surfactant loading seems to be related to the surfactant surface coverage that interacts by the $\mathrm{VdW}$ mechanism. As the zeta potential values are related to the external surface coverage, determination of the total specific surface area would elucidate the different

Table 3 Dapp, CA, and TSSA values of Mt sample and indicated products

\begin{tabular}{llll}
\hline Sample & Dapp $(\mathrm{nm})$ & $\mathrm{CA}\left({ }^{\circ}\right)$ & $\mathrm{TSSA}\left(\mathrm{m}^{2} / \mathrm{g}\right)$ \\
\hline $\mathrm{Mt}$ & $972.1 \pm 40$ & $57 \pm 2$ & $387 \pm 40$ \\
$\mathrm{OMt}-50$ & $2399 \pm 38^{*}$ & $75 \pm 2$ & $125 \pm 4 * *$ \\
$\mathrm{OMt}-100$ & $2802 \pm 50^{*}$ & $79 \pm 1$ & $84 \pm 2^{* *}$ \\
$\mathrm{Mt}_{300 \mathrm{~s}}$ & $1541 \pm 120$ & $48 \pm 1$ & $314 \pm 1$ \\
$\mathrm{OMt}_{300 \mathrm{~s}}-50$ & $1568 \pm 14$ & $68 \pm 2$ & $195 \pm 6$ \\
$\mathrm{OMt}_{300 \mathrm{~s}}-100$ & $3494 \pm 500$ & $64 \pm 2$ & $158 \pm 1$ \\
$\mathrm{Mt}_{600{ }^{\circ} \mathrm{C}}$ & $912 \pm 85$ & - & $88 \pm 4$ \\
$\mathrm{OMt}_{600^{\circ} \mathrm{C}}-50$ & $1529 \pm 240$ & $63 \pm 1$ & $56 \pm 1$ \\
$\mathrm{OMt}_{600}{ }^{\circ} \mathrm{C}-100$ & $2358 \pm 400$ & $51 \pm 1$ & $73 \pm 1$ \\
$\mathrm{Mt}_{950^{\circ} \mathrm{C}}$ & $453 \pm 24$ & - & - \\
$\mathrm{OMt}_{950^{\circ} \mathrm{C}}-50$ & $963 \pm 170$ & $146 \pm 4$ & - \\
$\mathrm{OMt}_{950^{\circ} \mathrm{C}}-100$ & $>\mathrm{LOQ}$ & $138 \pm 1$ & - \\
\hline
\end{tabular}

$>$ LOQ indicates $>$ limit of quantification

* Data from Gamba et al. (2015)

*** Data from Orta et al. (2019) behaviors found within the OMt and treated samples with organic loading.

\subsection{Apparent Equivalent Sphere Diameter, Contact} Angle, and Total Specific Surface Area Determinations

Table 3 summarizes the stable aggregate size, in $\mathrm{KCl}$ $10^{-3} \mathrm{M}$, indicated by Dapp values, and the evaluation of the hydrophilicity/hydrophobicity changes of Mt and its products performed by CA and TSSA measurements. The CA values for OMt-50 and OMt-100 samples were also added for comparative purposes.

The increase of Dapp values of Mt sample with ODTMA loading (Table 3) was assigned in previous work to micelle formation on the OMt external surface samples and the consequent electric charge changes that generated different interparticle attractions (Gamba et al. 2015).

The mechanical or thermal treatments performed on Mt sample caused opposite effects on the Dapp values. The increase in aggregate size found for the product attained by mechanical treatment was assigned previously to the structural damage produced by this treatment (Fernández et al. 2013). This behavior was confirmed in previous paragraphs (XRD analysis). However, a slight or twofold decrease in the aggregate size, compared with the Dapp value obtained for Mt sample, was found for samples fired up to $600{ }^{\circ} \mathrm{C}$ or $950{ }^{\circ} \mathrm{C}$, respectively. The different behaviors observed in the samples treated at different temperatures were validated by XRD results, which indicated the main collapse of 
Fig. 7 Zeta potential at $\mathrm{pH} 3$ vs the amount of surfactant loaded as $\mathrm{VdW}$ for (square) Mt, (circle) $\mathrm{Mt}_{300 \mathrm{~s}}$, and (up triangle) $\mathrm{Mt}_{600^{\circ} \mathrm{C}}$ samples. Symbols indicated the following: (half full) with 50 and (full) with $100 \% \mathrm{CEC}$

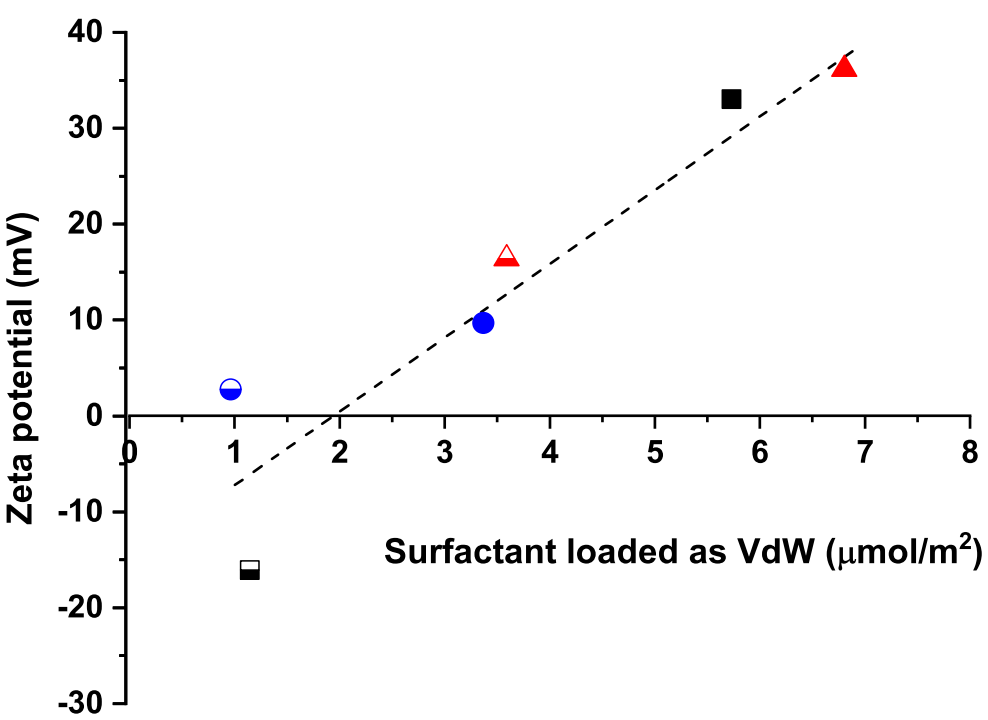

the interlayer produced at the lowest temperature, while the high destruction of the structure and the presence of cristobalite and spinel were evident with the thermal treatment at $950{ }^{\circ} \mathrm{C}$.

In samples previously treated with either of the two treatments, the additional surfactant loading increased Dapp values, following the same trend as samples with only surfactant loading (Table 3). This showed that the external surface behavior, as indicated by zeta potential values, and the changes due to surfactant loading drive the aggregation property.

The increase in CA values for ODTMA-loaded Mt samples (OMt-50 and OMt-100 samples) with respect to Mt confirms the increase of the hydrophobic property with respect to the hydrophilic surface of Mt sample (Zhao et al. 2017). It is important to note that a further surfactant increase to $200 \%$ CEC (OMt-200 sample) decreased the CA value to $59 \pm 1^{\circ}$, which indicated the reversal of the hydrophilic/hydrophobic state to a higher hydrophilic one.

The mechanical samples treated with further surfactant loading evidenced a decrease of CA (from 68 to $64^{\circ}$ ) with a lower amount (up to $100 \%$ CEC surfactant) than OMt samples, which would be a consequence of the structure modification shown by XRD analysis.

For $\mathrm{Mt}_{600^{\circ} \mathrm{C}}$ samples, the CA value could not be obtained due to the collapse of the basal space reversal by hydration (Önal 2007), while the surfactant loading up to $50 \% \mathrm{CEC}$ generated a $\mathrm{CA}$ value of $63^{\circ}$. The further surfactant loading increase $\left(\mathrm{OMt}_{600^{\circ} \mathrm{C}^{-1}}-0\right.$ sample) decreased the CA value to $51^{\circ}$, following a similar behavior to that found for $\mathrm{OMt}_{300 \mathrm{~s}}-50$ sample.

For $\mathrm{Mt}_{950^{\circ} \mathrm{C}}$ sample, the CA value could not be obtained, as happened with $\mathrm{Mt}_{600^{\circ} \mathrm{C}}$ sample. Almost no surfactant could be loaded in $\mathrm{OMt}_{950^{\circ} \mathrm{C}}-50$ and

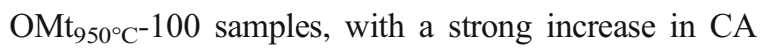
values attaining $146^{\circ}$ and $138^{\circ}$, respectively (Fig. S5, Online Resource 1).

The TSSA values generally decreased for all surfactant-loaded samples (Table 3) with respect to the respective base samples, which seems to be a consequence of the hydrophilic/hydrophobic property changes. Particularly, the increase in hydrophilic state for $\mathrm{OMt}_{600}{ }^{\circ} \mathrm{C}^{-100}$ compared with $\mathrm{OMt}_{600^{\circ} \mathrm{C}^{-50}}$ samples was evidenced by the $30-\mathrm{m}^{2} / \mathrm{g}$ increase of the TSSA value.

TSSA values for $\mathrm{OMt}_{950^{\circ} \mathrm{C}}$ and its surfactant-loaded samples could not be obtained. This might be assigned to the thermal treatment sintering of the samples (Tarasevich and Ovcharenko 1975).

To evidence the importance of the surfactant interactions as VdW mechanism at the external surface of the samples, the percentage amounts (Table 2) were converted to $\mu \mathrm{mol} / \mathrm{m}^{2}$ by using the TSSA values from Table 3. Figure 7 shows the zeta potential values at $\mathrm{pH}$ 3 (from Fig. 6) versus the surfactant coverage for all surfactant-loaded samples. The linear relation found in Fig. 7 shows the importance of the surfactant coverage in the electric charge developed at the external surface. 

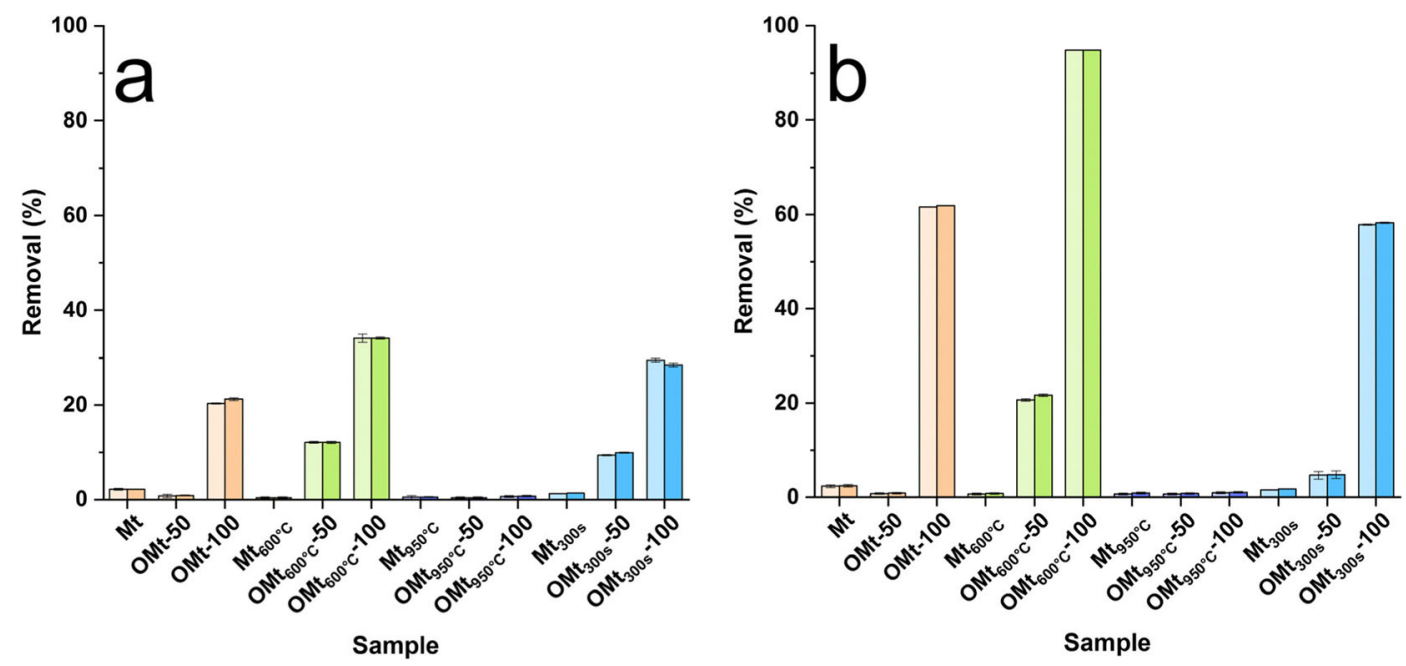

Fig. $8 \mathrm{Cr}(\mathrm{VI})$ (light colors) and $\mathrm{Cr}_{\text {Total }}$ (dark colors) removal at the indicated adsorbents, at $\mathrm{pH} 3$ and solid/liquid relation: a $1 \mathrm{~g} / \mathrm{L}$ and $\mathbf{b}$ $5 \mathrm{~g} / \mathrm{L}$

\subsection{Removal Efficiency of Cr(VI)}

Figure 8 shows the removal efficiency of Cr obtained for all the adsorbents for different solid/liquid ratios $(1 \mathrm{~g} / \mathrm{L}$ and $5 \mathrm{~g} / \mathrm{L})$. Due to the possibility of $\mathrm{Cr}(\mathrm{VI})$ reduction to $\mathrm{Cr}(\mathrm{III})$ upon sorption, $\mathrm{Cr}(\mathrm{VI})$ and $\mathrm{Cr}_{\text {Total }}$ were reported separately. The close removal efficiency data found for all studied samples of $\mathrm{Cr}(\mathrm{VI})$ and $\mathrm{Cr}_{\mathrm{Total}}$ indicated negligible reduction of $\mathrm{Cr}(\mathrm{VI})$ to $\mathrm{Cr}(\mathrm{III})$. Figure 8 also revealed the low removal percentage of $\mathrm{Cr}(\mathrm{VI})$ anions at $\mathrm{pH} 3$ on the negatively charged surface of the $\mathrm{Mt}$

Table 4 Zeta potential values before and after $\mathrm{Cr}(\mathrm{VI})$ removal at $\mathrm{pH} 5$

\begin{tabular}{lrr}
\hline \multirow{2}{*}{ Sample } & \multicolumn{2}{l}{ Zeta potential $(\mathrm{mV})$} \\
\cline { 2 - 3 } & Before removal & After removal \\
\hline $\mathrm{Mt}$ & $-35.05 \pm 1.94$ & $-31.44 \pm 0.60$ \\
$\mathrm{OMt}-50$ & $-28.23 \pm 1.12$ & $-29.13 \pm 0.80$ \\
$\mathrm{OMt}^{-100}$ & $25.26 \pm 1.83$ & $9.14 \pm 0.50$ \\
$\mathrm{Mt}_{300 \mathrm{~s}}$ & $-24.25 \pm 1.62$ & $-22.14 \pm 0.42$ \\
$\mathrm{OMt}_{300 \mathrm{~s}}-50$ & $-21.91 \pm 0.93$ & $-27.64 \pm 0.94$ \\
$\mathrm{OMt}_{300 \mathrm{~s}}-100$ & $-0.92 \pm 0.43$ & $-5.76 \pm 1.00$ \\
$\mathrm{Mt}_{600}{ }^{\circ} \mathrm{C}$ & $-34.42 \pm 1.59$ & $-34.65 \pm 1.12$ \\
$\mathrm{OMt}_{600}{ }^{\circ} \mathrm{C}-50$ & $-4.64 \pm 1.91$ & $-20.61 \pm 0.70$ \\
$\mathrm{OMt}_{600^{\circ} \mathrm{C}}-100$ & $27.31 \pm 2.40$ & $13.86 \pm 0.78$ \\
$\mathrm{Mt}_{950^{\circ} \mathrm{C}}$ & $-27.48 \pm 0.66$ & $-25.94 \pm 0.93$ \\
$\mathrm{OMt}_{950^{\circ} \mathrm{C}}-50$ & $-32.97 \pm 1.71$ & $-31.95 \pm 0.62$ \\
$\mathrm{OMt}_{950^{\circ} \mathrm{C}}-100$ & $-34.95 \pm 0.88$ & $-34.35 \pm 1.25$ \\
\hline
\end{tabular}

sample, as reported previously for similar clays (Dimos et al. 2012). Besides, the $\mathrm{Mt}_{300 \mathrm{~s}}, \mathrm{Mt}_{600^{\circ} \mathrm{C}}$, and $\mathrm{Mt}_{950^{\circ} \mathrm{C}}$ samples showed similar removal percentage to that of Mt sample, assigned also to their negatively charged external surfaces (Fig. 5). Particularly, for $\mathrm{Mt}_{950^{\circ} \mathrm{C}}$ sample, the almost-null surfactant loaded in $\mathrm{OMt}_{950^{\circ} \mathrm{C}}-50$

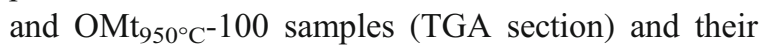
permanent negative zeta potential values (Fig. 6) did not contribute to enhancing $\mathrm{Cr}(\mathrm{VI})$ removal.

For samples with ODTMA exchanged, irrespective of the solid/liquid ratio and surfactant loading, it was observed that the general removal efficiency increased as follows: $\mathrm{OMt}<\mathrm{OMt}_{300 \mathrm{~s}}<\mathrm{OMt}_{600^{\circ} \mathrm{C}}$, in agreement with their surfactant loaded as $\mathrm{VdW}$ mechanism (Table 2), validating that the surface electric charge drives $\mathrm{Cr}(\mathrm{VI})$ anion sorption at $\mathrm{pH} 3$.

Although the solid/liquid ratio increased 5 times, the maximum $\mathrm{Cr}(\mathrm{VI})$ removal increase was 3 times and around 2.5 for $\mathrm{OMt}$ and $\mathrm{OMt}_{300 \mathrm{~s}}$ and $\mathrm{OMt}_{600^{\circ} \mathrm{C}}$, respectively, in agreement with the ratio of surfactant amount loaded assigned to VdW mechanism (Table 2). The lower $\mathrm{Cr}(\mathrm{VI})$ removal increase with respect to the solid/liquid ratio used could be assigned to a better dispersion factor produced by the lower solid/liquid ratio (Fig. 8a).

Particularly the $\mathrm{OMt}_{600^{\circ} \mathrm{C}}-100$ sample, with a solid/ liquid ratio of $5 \mathrm{~g} / \mathrm{L}$, showed the best $\mathrm{Cr}(\mathrm{VI})$ removal efficiency (95\%) (Fig. 8b). This amount being close to that reported in the literature by activated carbon (Xu et al. 2014; Zinicovscaia et al. 2014) and also by Mt exchanged with greater surfactant loading than our 
samples (Qurie et al. 2013; Thanos et al. 2012). This behavior reinforces the assumption indicated previously that the main driving force of the sorption of $\mathrm{Cr}(\mathrm{VI})$ was the positive surface electric charge generated at the external surface. To validate this assumption, zeta potential values were measured after $\mathrm{Cr}(\mathrm{VI})$ sorption in all samples (Table 4).

Although $\mathrm{Cr}(\mathrm{VI})$ removals were performed at $\mathrm{pH} 3$, the zeta potential values were compared at $\mathrm{pH} 5$, before and after $\mathrm{Cr}(\mathrm{VI})$ removal, because it was the $\mathrm{pH}$ obtained by resuspending the solid samples in the support electrolyte. A significant decrease in zeta potential values was observed for the samples that removed $\mathrm{Cr}(\mathrm{VI})$, evidencing its sorption on the external surface.

\section{Conclusions}

To enhance $\mathrm{Cr}(\mathrm{VI})$ retention at $\mathrm{pH} 3$, the current study investigates the surface modification of a raw montmorillonite, $\mathrm{Mt}$, subjected to two thermal pretreatments, $600{ }^{\circ} \mathrm{C}$ and $950{ }^{\circ} \mathrm{C}$ for $2 \mathrm{~h}$, or a mechanical grinding for $300 \mathrm{~s}$, and their subsequent exchange with an octadecyl trimethyl ammonium (ODTMA) loading at 50 and $100 \%$ of the Mt cation exchange capacity (CEC).

The absence of $\mathrm{Fe}^{2+}$ in the base materials revealed by Mössbauer analysis, excludes the possible $\mathrm{Cr}(\mathrm{VI})$ oxide reduction.

The deconvolution of the differential thermogravimetric analysis (DTGA) peaks within the temperature range 150 to $500{ }^{\circ} \mathrm{C}$ allowed to determine that in ODTMA-loaded Mt samples, a higher surfactant amount links to the internal surface by cation exchange than to the external surface by the Van der Waals mechanism. Contrary, ODTMA loaded in thermally or mechanically treated samples was majority located at external surface by the Van der Waals mechanism, probably related to the collapse or damage of the Mt interlayer space.

X-ray diffraction (XRD) analyses indicate that the surfactant access to the interlayer reversed the collapse of the basal space for samples fired at $600{ }^{\circ} \mathrm{C}$, while delamination did not improve for mechanically treated samples.

The zeta potential values at $\mathrm{pH} 3$ are directly related to the external surface coverage by the surfactant. When $100 \%$ of the CEC surfactant is loaded, the $600{ }^{\circ} \mathrm{C}$ treated and the raw Mt samples attain a higher positive zeta potential than the mechanically treated products.
This is related to the enhancement of $\mathrm{Cr}(\mathrm{VI})$ removal. The zeta potential values show that only samples that remove $\mathrm{Cr}(\mathrm{VI})$ decrease their positive values.

For both solid/liquid ratios studied, the best sample for $\mathrm{Cr}(\mathrm{VI})$ removal is $\mathrm{OMt}_{600^{\circ} \mathrm{C}^{-100}}$, due to its higher surfactant percentage at the external surface, a consequence of the interlayer collapse. As a first approach, the electrostatic mechanism can be assigned as the main driving force for $\mathrm{Cr}(\mathrm{VI})$ sorption on the surface of modified Mt clays. These results are evidence that thermally treated Mt clays have a greater potential as low cost adsorbents than untreated Mt, improving the retention of $\mathrm{Cr}(\mathrm{VI})$ at the external surface and using less surfactant.

The current results demonstrate that by pretreating the montmorillonite surface so as to make the surfactant lie at the external surface, the retention of $\mathrm{Cr}(\mathrm{VI})$ is greatly improved. This method reduces the amount of surfactant to less than half for similar removal efficiency of $\mathrm{Cr}(\mathrm{VI})$ obtained by other studies. More research is needed to achieve the optimal solid/liquid dose.

Funding Information This study received financial support from the Argentinian Ministry of Science, Technology and Productive Innovation (MINCyT) and the National Agency for Scientific and Technological Promotion (ANPCyT), PICT-20140585. M.L. Montes, R.C. Mercader, G. Curutchetm and R.M. Torres Sanchez are members of the National Council for Scientific and Technological Research (CONICET). C. Fernández Morantes and F. Yarza received support from the CONICET fellowship.

\section{References}

Bajda, T., \& Kłapyta, Z. (2013). Adsorption of chromate from aqueous solutions by HDTMA-modified clinoptilolite, glauconite and montmorillonite. Applied Clay Science, 86, 169173. https://doi.org/10.1016/j.clay.2013.10.005.

Bianchi, A. E., Fernández, M., Pantanetti, M., Viña, R., Torriani, I., Sánchez, R. M. T., et al. (2013). ODTMA+ and HDTMA+ organo-montmorillonites characterization: new insight by WAXS, SAXS and surface charge. Applied Clay Science, 83-84, 280-285. https://doi.org/10.1016/j.clay.2013.08.032.

Christidis, G. E., Makri, P., \& Perdikatsis, V. (2004). Influence of grinding on the structure and colour properties of talc, bentonite and calcite white fillers. [Article]. Clay Minerals, 39 (2), 163-175. https://doi.org/10.1180 /0009855043920128.

Clescerl, L. S., Greenberg, A. E., \& Eaton, A. D. (1998). APHA standard methods for the examination of water and wastewater. Washington DC: American Public Health Association.

Costa, T. C. D. C., Melo, J. D. D., \& Paskocimas, C. A. (2013). Thermal and chemical treatments of montmorillonite clay. 
[Article]. Ceramics International, 39(5), 5063-5067. https://doi.org/10.1016/j.ceramint.2012.11.105.

de Paiva, L. B., Morales, A. R., \& Valenzuela Díaz, F. R. (2008). Organoclays: properties, preparation and applications. [review]. Applied Clay Science, 42(1-2), 8-24. https://doi. org/10.1016/j.clay.2008.02.006.

Dellisanti, F., \& Valdré, G. (2005). Study of structural properties of ion treated and mechanically deformed commercial bentonite. [Article]. Applied Clay Science, 28(1-4 SPEC. ISS), 233244. https://doi.org/10.1016/j.clay.2003.12.036.

Dimos, V., Haralambous, K., \& Malamis, S. (2012). A review on the recent studies for chromium species adsorption on raw and modified natural minerals. Critical Reviews in Environmental Science and Technology, 42(19), 19772016. https://doi.org/10.4236/ajac.2013.47A002.

Djukić, A., Jovanović, U., Tuvić, T., Andrić, V., Grbović Novaković, J., Ivanović, N., et al. (2013). The potential of ball-milled Serbian natural clay for removal of heavy metal contaminants from wastewaters: simultaneous sorption of $\mathrm{Ni}$, $\mathrm{Cr}, \mathrm{Cd}$ and $\mathrm{Pb}$ ions. [Article]. Ceramics International, 39(6), 7173-7178. https://doi.org/10.1016/j.ceramint.2013.02.061.

Dultz, S., An, J.-H., \& Riebe, B. (2012). Organic cation exchanged montmorillonite and vermiculite as adsorbents for $\mathrm{Cr}(\mathrm{VI})$ : Effect of layer charge on adsorption properties. Applied Clay Science, 67-68, 125-133. https://doi.org/10.1016/j. clay.2012.05.004.

Emmerich, K., Madsen, F. T., \& Kahr, G. (1999). Dehydroxylation behavior of heat-treated and steam-treated homoionic cisvacant montmorillonites. [Article]. Clays and Clay Minerals, 47(5), 591-604. https://doi.org/10.1346 /CCMN.1999.0470506.

Emmerich, K., Steudel, A., \& Merz, D. (2017). Dehydroxylation of dioctahedral smectites in water vapor atmosphere. [Article]. Applied Clay Science, 137, 1-5. https://doi. org/10.1016/j.clay.2016.12.003.

España, V. A. A., Sarkar, B., Biswas, B., Rusmin, R., \& Naidu, R. (2019). Environmental applications of thermally modified and acid activated clay minerals: current status of the art. [article]. Environmental Technology and Innovation, 13, 383-397. https://doi.org/10.1016/j.eti.2016.11.005.

Fernández, M., Alba, M. D., \& Torres Sánchez, R. M. (2013). Effects of thermal and mechanical treatments on montmorillonite homoionized with mono- and polyvalent cations: insight into the surface and structural changes. [article]. Colloids and Surfaces A: Physicochemical and Engineering Aspects, 423, 1-10. https://doi.org/10.1016/j. colsurfa.2013.01.040.

Gamba, M., Flores, F. M., Madejová, J., \& Sánchez, R. M. T. (2015). Comparison of imazalil removal onto montmorillonite and nanomontmorillonite and adsorption surface sites involved: An approach for agricultural wastewater treatment. [Article]. Industrial and Engineering Chemistry Research, 54(5), 1529-1538. https://doi.org/10.1021/ie5035804.

Hedley, C. B., Yuan, G., \& Theng, B. K. G. (2007). Thermal analysis of montmorillonites modified with quaternary phosphonium and ammonium surfactants. [article]. Applied Clay Science, 35(3-4), 180-188. https://doi.org/10.1016/j. clay.2006.09.005.

Hrachová, J., Komadel, P., \& Fajnor, V. Š. (2007). The effect of mechanical treatment on the structure of montmorillonite.
Materials Letters, 61(16), 3361-3365. https://doi. org/10.1016/j.matlet.2006.11.063.

Huang, P., Kazlauciunas, A., Menzel, R., \& Lin, L. (2017). Determining the mechanism and efficiency of industrial dye adsorption through facile structural control of organomontmorillonite adsorbents. ACS Applied Materials \& Interfaces, 9(31), 26383-26391. https://doi.org/10.1021 /acsami.7b08406.

Jayrajsinh, S., Shankar, G., Agrawal, Y. K., \& Bakre, L. (2017). Montmorillonite nanoclay as a multifaceted drug-delivery carrier: a review. [review]. Journal of Drug Delivery Science and Technology, 39, 200-209. https://doi. org/10.1016/j.jddst.2017.03.023.

Johnston, J. H., \& Cardile, C. M. (1987). Iron substitution in montmorillonite, illite, and glauconite by $57 \mathrm{Fe}$ Mossbauer spectroscopy. [article]. Clays \& Clay Minerals, 35(3), 170176. https://doi.org/10.1346/CCMN.1987.0350302.

Júnior, J. A. A., \& Baldo, J. B. (2014). The behavior of zeta potential of silica suspensions. New Journal of Glass and Ceramics, 4(02), 29. https://doi.org/10.4236 /njgc.2014.42004.

Lagarec, K., \& Rancourt, D. G. (1998). Recoil-Mössbauer spectral analysis software for sWindows. Ottawa: University Ottawa.

Madejová, J., Pálková, H., \& Jankovič, L'. (2012). Degradation of surfactant-modified montmorillonites in $\mathrm{HCl}$. [article]. Materials Chemistry and Physics, 134(2-3), 768-776. https://doi.org/10.1016/j.matchemphys.2012.03.067.

Magnoli, A. P., Tallone, L., Rosa, C. A. R., Dalcero, A. M., Chiacchiera, S. M., \& Torres Sanchez, R. M. (2008). Commercial bentonites as detoxifier of broiler feed contaminated with aflatoxin. [article]. Applied Clay Science, 40(14), 63-71. https://doi.org/10.1016/j.clay.2007.07.007.

Martignago, F., Andreozzi, G., \& Negro, A. D. (2006). Thermodynamics and kinetics of cation ordering in natural and synthetic $\mathrm{Mg}(\mathrm{Al}, \mathrm{Fe} 3+) 2 \mathrm{O} 4$ spinels from in situ hightemperature X-ray diffraction. American Mineralogist, 91(23), 306-312. https://doi.org/10.2138/am.2006.1880.

Missana, T., \& Adell, A. (2000). On the applicability of DLVO theory to the prediction of clay colloids stability. [article]. Journal of Colloid and Interface Science, 230(1), 150-156. https://doi.org/10.1006/jcis.2000.7003.

Murad, E., \& Cashion, J. (2004). Mössbauer spectroscopy of environmental materials and their industrial utilization (1st ed.). Norwell, Massachusetts: Kluwer Academic Publishers.

Önal, M. (2007). Swelling and cation exchange capacity relationship for the samples obtained from a bentonite by acid activations and heat treatments. [article]. Applied Clay Science, 37(1-2), 74-80. https://doi.org/10.1016/j. clay.2006.12.004.

Orta, M. D. M., Flores, F. M., Morantes, C. F., Curutchet, G., \& Torres Sánchez, R. M. (2019). Interrelations of structure, electric surface charge, and hydrophobicity of organo-mica and -montmorillonite, tailored with quaternary or primary amine cations. Preliminary study of pyrimethanil adsorption. [article]. Materials Chemistry and Physics, 223, 325-335. https://doi.org/10.1016/j.matchemphys.2018.10.059.

Patel, H. A., Somani, R. S., Bajaj, H. C., \& Jasra, R. V. (2006). Nanoclays for polymer nanocomposites, paints, inks, greases and cosmetics formulations, drug delivery vehicle and waste 
water treatment. [article]. Bulletin of Materials Science, 29(2), 133-145. https://doi.org/10.1007/BF02704606.

Pecini, E. M., \& Avena, M. J. (2013). Measuring the isoelectric point of the edges of clay mineral particles: the case of montmorillonite. [article]. Langmuir, 29(48), 14926-14934. https://doi.org/10.1021/la403384g.

Pérez-Rodríguez, J. (2003). Transformation of clay minerals on grinding: A review. In J. Pérez-Rodríguez (Ed.), Applied study of cultural heritage and clays (pp. 425-444). Madrid: Servicio Publicaciones del CSIC.

Praus, P., Turicová, M., Študentová, S., \& Ritz, M. (2006). Study of cetyltrimethylammonium and cetylpyridinium adsorption on montmorillonite. Journal of Colloid and Interface Science, 304(1), 29-36.

Qurie, M., Khamis, M., Manassra, A., Ayyad, I., Nir, S., Scrano, L., et al. (2013). Removal of Cr (VI) from aqueous environments using micelle-clay adsorption. The Scientific World Journal, 2013. https://doi.org/10.1155/2013/942703.

Rasband, W. (1997). ImageJ, US National Institutes of Health, Bethesda, Maryland, USA. https://imagej.nih.gov/ij (Vol. 2012).

Rosen, M. J., \& Kunjappu, J. T. (2012). Surfactants and interfacial phenomena (4th ed.). New Jersey: John Wiley \& Sons.

Sarkar, B., Naidu, R., \& Megharaj, M. (2013). Simultaneous adsorption of tri- and hexavalent chromium by organoclay mixtures topical collection on remediation of site contamination. [article]. Water, Air, and Soil Pollution, 224(12). https://doi.org/10.1007/s11270-013-1704-0.

Savas, L. A., \& Hancer, M. (2015). Montmorillonite reinforced polymer nanocomposite antibacterial film. Applied Clay Science, 108, 40-44.

Schampera, B., Tunega, D., Šolc, R., Woche, S. K., Mikutta, R., Wirth, R., et al. (2016). External surface structure of organoclays analyzed by transmission electron microscopy and X-ray photoelectron spectroscopy in combination with molecular dynamics simulations. Journal of Colloid and Interface Science, 478, 188-200. https://doi.org/10.1016/j. jcis.2016.06.008.

Schoonheydt, R. A., Johnston, C. T., \& Bergaya, F. (2018). Clay minerals and their surfaces. Developments in Clay Science, 9 , $1-21$.

Stalder, A. F., Melchior, T., Müller, M., Sage, D., Blu, T., \& Unser, M. (2010). Low-bond axisymmetric drop shape analysis for surface tension and contact angle measurements of sessile drops. Colloids and Surfaces A: Physicochemical and Engineering Aspects, 364(1), 72-81. https://doi.org/10.1016 /j.colsurfa.2010.04.040.

Tarasevich, Y. I., \& Ovcharenko, F. (1975). Adsorption on clay minerals. Kiev: Naukova Dumka.

Thanos, A. G., Katsou, E., Malamis, S., Psarras, K., Pavlatou, E. A., \& Haralambous, K. J. (2012). Evaluation of modified mineral performance for chromate sorption from aqueous solutions. [article]. Chemical Engineering Journal, 211212, 77-88. https://doi.org/10.1016/j.cej.2012.08.086.

Thomas, F., Michot, L. J., Vantelon, D., Montargès, E., Prélot, B., Cruchaudet, M., et al. (1999). Layer charge and electrophoretic mobility of smectites. [conference Paper]. Colloids and Surfaces A: Physicochemical and Engineering Aspects, 159(2-3), 351-358. https://doi.org/10.1016/S0927-7757(99 )00291-5.
Torres Sánchez, R. M. (1997). Mechanochemical effects on physicochemical parameters of homoionic smectite. [article]. Colloids and Surfaces A: Physicochemical and Engineering Aspects, 127(1-3), 135-140. https://doi.org/10.1016/S09277757(97)00105-2.

Torres Sánchez, R. M., \& Falasca, S. (1997). Specific surface area and surface charges of some Argentinian soils. [article]. Journal of Plant Nutrition and Soil Science, 160(2), 223226. https://doi.org/10.1002/jpln.19971600216.

Torres Sánchez, R. M., Genet, M. J., Gaigneaux, E. M., dos Santos Afonso, M., \& Yunes, S. (2011). Benzimidazole adsorption on the external and interlayer surfaces of raw and treated montmorillonite. Applied Clay Science, 53(3), 366-373. https://doi.org/10.1016/j.clay.2010.06.026.

Uddin, M. K. (2017). A review on the adsorption of heavy metals by clay minerals, with special focus on the past decade. Chemical Engineering Journal, 308, 438-462. https://doi. org/10.1016/j.cej.2016.09.029.

Wang, S. L., Chen, C. C., Tzou, Y. M., Hsu, C. L., Chen, J. H., \& Lin, C. F. (2009). A mechanism study of light-induced $\mathrm{Cr}(\mathrm{VI})$ reduction in an acidic solution. [article]. Journal of Hazardous Materials, 164(1), 223-228. https://doi. org/10.1016/j.jhazmat.2008.07.145.

Wang, G., Hua, Y., Su, X., Komarneni, S., Ma, S., \& Wang, Y. (2016). Cr(VI) adsorption by montmorillonite nanocomposites. [article]. Applied Clay Science, 124-125, 111-118. https://doi.org/10.1016/j.clay.2016.02.008.

Xu, C. H., Zhu, L. J., Wang, X. H., Lin, S., \& Chen, Y. M. (2014). Fast and highly efficient removal of chromate from aqueous solution using nanoscale zero-valent iron/activated carbon (NZVI/AC). [article]. Water, Air, and Soil Pollution, 225(2). https://doi.org/10.1007/s11270-013-1845-1.

Yamagata, S., Hamba, Y., Akasaka, T., Ushijima, N., Uo, M., Iida, J., et al. (2012). The effect of enhancing the hydrophobicity of OMMT on the characteristics of PMMA/OMMT nanocomposites. Applied Surface Science, 262, 56-59. https://doi. org/10.1016/j.apsusc.2012.01.081.

Yariv, S. (2001). IR spectroscopy and thermo-IR spectroscopy in the study of the fine structure of organo-clay complexes. In S. Yariv \& H. Cross(Eds.)Organo-clay complexes and interactions (pp. 357-474): CRC Press.

Zhang, Y., Zhao, Y., Zhu, Y., Wu, H., Wang, H., \& Lu, W. (2012). Adsorption of mixed cationic-nonionic surfactant and its effect on bentonite structure. [article]. Journal of Environmental Sciences (China), 24(8), 1525-1532. https://doi.org/10.1016/S1001-0742(11)60950-9.

Zhao, Q., Choo, H., Bhatt, A., Burns, S. E., \& Bate, B. (2017). Review of the fundamental geochemical and physical behaviors of organoclays in barrier applications. [article]. Applied Clay Science, 142, 2-20. https://doi.org/10.1016/j. clay.2016.11.024.

Zinicovscaia, I., Mitina, T., Lupascu, T., Duca, G., Frontasyeva, M. V., \& Culicov, O. A. (2014). Study of chromium adsorption onto activated carbon. [article]. Water, Air, and Soil Pollution, 225(3). https://doi.org/10.1007/s11270-0141889-x.

Publisher's Note Springer Nature remains neutral with regard to jurisdictional claims in published maps and institutional affiliations. 